Petre, C. E. (2021). The relationship between Internet use and self-concept clarity: A systematic review and meta-analysis. Cyberpsychology: Journal of Psychosocial Research on Cyberspace, 15(2), Article 4.

\title{
The Relationship Between Internet Use and Self-Concept Clarity: A Systematic Review and Meta-Analysis
}

\author{
Cristina Elena Petre \\ Department of Psychology, University of Bucharest, Bucharest, Romania
}

\begin{abstract}
There are three hypotheses regarding the relationship between Self-Concept Clarity (SCC) and Internet use. It was argued that Internet use: 1) decreases SCC, 2) increases SCC, 3) does not relate with SCC. The present study, in the form of a systematic and meta-analytic synthesis, aimed to explore: a) the extent empirical evidence can support each hypothesis; $b$ ) how Internet use-SCC relationship was addressed across studies; $c$ ) the intensity of the Internet use -SCC relationship; d) potential moderators. Twenty-one studies $(N=8,910)$ met the inclusion criteria for the systematic review (i.e., being quantitative, written in English, concerned with Internet use-SCC relationship) and 11 studies $(N=3,298)$ met the additional criteria for meta-analysis (i.e., being correlational, using self-evaluation instruments, quantifying general Internet use and including the information needed to calculate the meta-analysis specific indicators). Results emphasized that all three hypotheses are plausible, as distinct dimensions of Internet use related differently with SCC. However, the conclusions were limited by the extensive use of cross-sectional design. For general Internet use and SCC relationship the overall effect was $-0.350, p<.01$. Some moderators were significant: cultural background, Internet operationalization, age homogeneity, participants rewarding. This paper outlines the complexity of SCC - Internet relationship and underlines some of the gaps that should be further addressed. Implications and limits of the study (e.g., publication bias, excluded outcomes in the meta-analysis or possible omission of moderators) are discussed.
\end{abstract}

Keywords: Internet; self-concept clarity; fragmentation; unity; systematic review; meta-analysis

\section{Introduction}

With more than 4 billion users worldwide (Clement, 2019), the Internet gave rise to a new, digital generation with its own characteristics (Palfrey \& Gasser, 2008). Far from being just a leisure activity, the use of Internet leaves a mark on how young people define themselves (Choi et al., 2018). This paper is aimed at carrying out a systematic and a meta-analytic review to investigate the relationship between Self-Concept Clarity (SCC) and the online environment.

When considering the association between Internet use and self-concept, some studies focused on the content of the self-concept (i.e., attributes), while others focused on its structural dimension, namely SCC. SCC takes into account the extent to which the contents of the self are clearly defined, consistent and stable in time (Campbell, 1990). It implies the following:

(a) a given individual's understanding of his or her personal attributes, (b) the degree to which this individual views his or her personal attributes as harmonious with one another, or (c) the degree to which this individual views these attributes as continuous and coherent across contexts and through time. (Dunlop, 2017, p. 20) 
One of the sources of SCC is confirmation of self-beliefs (Hertel, 2017). The Internet may offer many opportunities both for clarifying these self-beliefs (e.g., through identity experiments), and for their confirmation (e.g., through interpersonal communication, self-disclosure, social comparison or feedback from other people).

Although Valkenburg and Peter (2011) identified only three studies which addressed the relationship between Internet use and SCC, the focus on this topic has increased since the publication of their initial article. Some authors (e.g., Valkenburg \& Peter, 2008) argued that, once certain variables were controlled (i.e., social anxiety, loneliness, variety of communication partners), the association between SCC and Internet use was not significant. On the contrary, other studies have highlighted the existence of a relationship between the two variables. Nevertheless, there are two different assumptions regarding how the use of Internet relates to SCC: the selfconcept fragmentation hypothesis and the self-concept unity hypothesis (Valkenburg \& Peter, 2011).

According to the self-concept fragmentation hypothesis, the use of the Internet predicts a low SCC (e.g., Appel et al., 2018). The explanation is that the Internet provides a large variety of potential interaction partners, as well as multiple ways of experimenting with identity (Valkenburg \& Peter, 2011). Exposed to a variety of roles and values, users, particularly adolescents, find it difficult to synthesize all options in a coherent and unitary self, especially when exploration is ruminative and not motivated by curiosity (Yang \& Brown, 2016). In this case, overexposed to others' ideas, opinions and feedback, one can begin to have doubts about their true identity (Valkenburg \& Peter, 2008). Moreover, due to the disinhibition effect (i.e., expressing thoughts, feelings, behaviors in uncharacteristic ways compared to offline life), people may project in online space hidden aspects of their personality; if their selfconcept is already fragmented, these new aspects will not be integrated in an unitary self-structure, further facilitating self fragmentation (Gackenbach \& von Stackelberg, 2007). One of the few longitudinal studies on this subject confirmed the hypothesis of fragmentation, highlighting that increased use of Facebook predicted a decrease of SCC in time (Appel et al., 2018).

The self-concept unity hypothesis, however, advances the idea that Internet use predicts a clearer self-concept (Valkenburg \& Peter, 2011). For example, SCC was positively predicted by the number of likes received on Facebook and it was higher for people that managed their Facebook photos more frequently (Drogos, 2015). According to self-affirmation theory, people aim at preserving self-integrity and self-worth by communicating self-related aspects and by receiving feedback that validate their self-concept (Steele, 1988). This explains why activities such as posting on Facebook and receiving appreciations are related with a stable and clear self-concept. Moreover, exercising autonomy, discovering one's own interests, creating avatars or belonging to certain online communities are just a few elements that are possible on the Internet and that contribute to a greater SCC by facilitating the processes of self-reflection, self-exploration and identification with others (Borca et al., 2015; Guegan et al., 2015; Šporčić \& Glavak-Tkalić, 2018).

At an initial analysis, current research emphasizes both a positive and a negative relationship between Internet use and SCC. However, many studies addressing this issue are correlational. This means that adhering to one hypothesis or another while interpreting the results is more of a hypothetical process. Consequently, in absence of rigorous causal studies, the same association can be interpreted in opposite ways. For instance, negative correlations are usually explained through the self-fragmentation hypothesis. However, they also could reflect that people with low SCC use the Internet more in order to find helpful information for clarifying their identity (Israelashvili et al., 2012), which is in line with the self-concept unity hypothesis, and in contrast with the fragmentation one. Therefore, one research question of this study was:

RQ1: To what degree the existing empirical evidence supports each of the hypotheses?

In order to answer this question, several aspects were considered. First, there has been a confusion regarding the directionality of the relationship between the two variables. Is the use of Internet influencing SCC, is SCC determining the use of Internet or is there a reciprocal relationship between the two? But most importantly, are there enough studies that allow for conclusions about directionality? As it was noted above, the direction of the Internet use-SCC relationship can easily change the interpretation of the results, favoring one hypothesis over another. In this context, a more specific research question was:

RQ1.1: Can the directionality of the relationship between the two variables be inferred from the current studies? 
Another element that should be considered when speaking about empirical evidence is the quality of the studies. For example, results may be distorted if the instruments used have poor psychometric characteristics or have not been adapted to the culture in which they were applied. The sample size (too small or too large) also influences the results obtained. Therefore, another question was:

RQ1.2: What is the quality of evidence brought for each hypothesis?

Apart from what empirical evidence really emphasizes regarding the relationship between SCC-Internet use, contradictory results can still be observed, at least in terms of positive/negative associations or significant/insignificant ones. This can be also due to the fact that Internet is a general subject, and many aspects can be studied in conjunction with it. For example, a distinction can be made between several types of activities carried out, such as impression management, social comparisons, social interactions (Shapiro \& Margolin, 2014) or immersion in the virtual reality of video games (Šporčić \& Glavak-Tkalić, 2018). Each of these activities can relate differently with SCC. So, another question of the research was:

RQ2: Regarding the relationship between SCC and Internet, how was the latter operationalized and how was this reflected in relation with SCC?

Assuming there is an association between SCC and certain aspects of the Internet, it is necessary to know how strong it actually is.

RQ3: What is the intensity of the relationship between Internet use and SCC?

Not least, potential moderators should be considered. Culture is one of such moderators. For example, individualistic societies put more emphasis on individualism, stability or consistency when defining the self, whereas in collectivistic societies, the self is defined as being more flexible and dependent on the social context (Campbell et al., 1996). In other words, in individualistic cultures there is less tolerance for self-incongruities, so people can put more effort into improving SCC, including through a more intense use of the Internet. For this reason, Internet use-SCC relationship is expected to be stronger in individualistic cultures. In line with this idea, Quinones and Kakabadse (2015a) pointed out that the association between SCC and compulsive use of the Internet was weaker for the United Arab Emirates than for the United States of America.

Another element that could influence the results is the age of the participants. More specifically, the self-concept becomes more stable and more clear with aging, but around the age of 60, SCC begins to diminish again (LodiSmith \& Roberts, 2010). In addition, young people use the Internet more than adults (Eurostat, 2016). Consequently, the relationship between SCC and the online environment is expected to be stronger for younger people.

The results may also be influenced by whether participants have received a reward following their participation in the research. Sharp et al. (2006) highlighted that people who volunteered to participate in a research had higher self-determination than non-participants. But when a reward was given, differences between participants and non-participants were no longer significant. As a more self-determinant individual may be willing to invest more in increasing SCC, it is interesting to explore whether the existence of a reward moderates the Internet use-SCC relationship.

Summarizing, another question of this research was:

RQ4: How much does the relationship between SCC and the use of Internet vary across studies?

RQ4.1: What moderators could explain this variation?

Concluding, the present study aimed to a) explore how the Internet use-SCC relationship was addressed across different studies, b) synthesize the conflicting results and c) find a consensus. For this, a systematic review of literature was conducted, followed by a meta-analysis. The answers to these questions were obtained by summarizing, integrating and interpreting the results of different empirical research. 
Finding consensus on contradictory hypotheses is essential to understand the extent to which the virtual environment facilitates or prevents the development of a clear self-concept. This is important considering that lack of self-concept clarity has been associated with multiple negative outcomes, including internalization disorders (Van Dijk et al., 2014), eating disorders (Vartanian \& Dey, 2013), psychotic disorders (e.g., Cicero, 2018) and poor conflict management abilities (Bechtoldt et al., 2010). As the Internet is part of everyday life, especially that of young people, understanding its role in the self-concept development can help specialists decide whether Internet can be used to support an intervention or it should be considered a risk to be prevented.

At a theoretical level, the paper aims at improving knowledge about self-concept development by taking into consideration some of the changes in the contemporary society, such as the popularization of the Internet.

\section{Method}

Systematic review and meta-analysis were conducted following the PRISMA guidelines (Moher et al., 2009). There was no protocol published before the review was conducted.

The following supplemental materials are provided: characteristics of the studies included (see Appendix A, Table S1), the checklist for the quality assessment (see Appendix A, Table S2), the results for each study regarding their quality (see Appendix A, Table S3) and the PRISMA Checklist (see Appendix B).

\section{Search Strategy}

Study selection was made from August 2018 to September 2020. The search engine provided by the National University of Singapore (NUS) was mainly used to search for articles. The NUS engine explored relevant databases such as Elsevier, Medline, PubMed, ProQuest, Sociological Databases, Springer Science \& Business Media. It took into account journal articles, conference papers, manuscripts, posters or presentations, theses / dissertations, books chapters, transcripts, and reports. PsychInfo and Science Direct databases, and Open Gray site were also used. Search terms included: ("self-concept clarity" OR "self-concept unity" OR "self-concept fragmentation" OR "self-concept *certainty" OR "self-concept confusion" OR "self-concept congruence") AND ("Internet" OR "social networking" OR "online video gaming" OR "Facebook" OR "Instagram" OR "online"). Some of these terms were added after exploring the keywords of relevant articles for the topic.

To improve the quality of the search some alternative strategies were used: a) investigation of the bibliographic references of selected articles or of syntheses related to the current theme; b) searching for new articles among those which have cited the articles already selected (Google Scholar was used); c) contacting the authors through e-mail and requesting an English version of the full article, when the publications were in a different language but the abstract seemed to offer good insight or when the work was in a form of a poster; d) contacting authors on the current theme and asking for unpublished articles.

\section{Study Selection and Eligibility Criteria}

Studies were screened based on the information in the title and in the abstract. If this information was insufficient to make a decision, the full article was downloaded for further assessment. The inclusion criteria were as follows:

a) quantitative, empirical studies;

b) studies which included SCC and the Internet as variables. For SCC, studies that used other terminology (e.g., "unity of the self-concept", "clarification of the ego", "the certainty of the self-concept", etc.), were taken into account as long as the construct was operationalized according to the definition of Campbell et al. (1996): the clarity of the self-concept is the extent to which the contents of the self are clearly defined, consistent and stable over time. Regarding the Internet, studies were considered when the focus was on Internet use in general, on social networks or on online video games;

c) the articles were written in English; 
For the meta-analysis, the articles selected had to meet the following additional criteria:

d) the studies were correlational;

e) variables were measured by self-report instruments;

f) the studies quantified a general use of the Internet; this may have included time spent in the online environment or more complex aspects such as addiction, compulsive use, intensity of use;

g) the studies included the information needed to calculate meta-analysis specific indicators.

Criteria d), e) and f) were formulated based on the most common elements of the studies, which had been outlined in the systematic review. The purpose was to ensure the inclusion of comparable, homogenous studies in the meta-analysis.

Two evaluators independently verified whether the resulting articles met the eligibility criteria outlined above. Both of them were informed about the purpose of the study. Inter-rater agreement was very good (Cohen's $k=$ 0.85). Any disagreement on the articles' eligibility was resolved through discussion, with the possibility of contacting a third evaluator if the two initial evaluators did not reach an agreement.

\section{Extracting Data}

The information from the studies was coded by the author according to a previously developed scheme, and it was checked by a second evaluator. Any misunderstanding was resolved through discussion. The data coding scheme included: author of the study, year of publication, type of the design, country where the data was collected, demographic characteristics of the sample (number, gender), whether the participants were rewarded, variables, instruments used to measure variables and results.

\section{Assessing Quality of Included Studies and Risk of Bias}

Two evaluators independently assessed the studies' quality and risk of bias and any disagreements were resolved through discussion. For the evaluation criteria, a checklist was created (see Table S2), with items mainly adapted from the JBI Critical Appraisal Checklist for Analytical Cross Sectional Studies (Moola et al., 2017). Some items were inspired by the STROBE statement for reporting observational studies (Vandenbroucke et al., 2007). The evaluator could check for each criterion the extent to which it was met: "yes" (3 points), "no" (0 points), "incomplete or unclear" (1 or 2 points depending on its considered impact on quality of the study), "does not apply". Each option had a corresponding number of points which allowed for calculating a total score. The evaluator also had an "Observations" column to mention the reasons for granting fewer points. Each evaluator received an additional table with explanations for each item.

Poor quality studies were also considered for the systematic review, which sought to provide an overview of the current state of research on the relationship between SCC and the use of Internet. In this respect, when necessary, attention was drawn to the interpretation of the results, mentioning when they should be viewed with caution. However, such studies were not included in the meta-analysis.

\section{Data Synthesis Strategy}

The first step was to make a systematic synthesis of the results. The synthesis focused on studies' characteristics and results regarding the relationship between SCC and the use of Internet. A single article (Appel et al., 2018) comprised of several independent studies, all respecting the eligibility criteria. Therefore, they were treated separately in the analysis.

Subsequently, a meta-analysis model with random effects was conducted. This type of model was chosen because it was assumed that part of the studies' dispersion reflected real differences between the reported effect sizes, as studies were carried out by independent researchers, in different contexts and on different populations. Taking 
into account the diversity of issues investigated about the Internet, studies addressing the relationship between SCC and a more general use of the Internet were selected to ensure homogeneity between studies. The general use of the Internet has been one of the most commonly referred aspects in studies and it has been conceptualized as dependence, intensity, compulsive use, time spent online.

Comprehensive Meta-Analysis (Version 2.0; Borenstein et al., 2005) was used for the statistical analyses. Since all studies were correlational, the effect sizes included in the analysis were the correlation coefficients $r$, reported in the studies. Values have been converted to Fisher's z values, and the overall effect was again transformed into the correlation coefficient $r$ and reported as such. For studies where the results were presented separately according to the cultural environment of the participants, the unit of analysis was the subgroups concerned and not the study as a whole. The basis for this decision was the interest in the cultural environment as a potential moderator of the Internet use-SCC relationship. If the studies reported multiple outcomes, the mean of effects was used in the analysis. The degree of heterogeneity between studies was estimated using a statistical test based on $Q$ and $R^{2}$. A value greater than $50 \%$ for $R^{2}$ was considered to be indicative of substantial heterogeneity, in which case potential moderators were tested. Subgroups analyses and meta-regressions were conducted. Also, the risk for publication bias was evaluated. 95\% confidence intervals and thresholds of significance (bilateral) were reported for results.

\section{Publication Bias}

In order to control the publication bias as much as possible, a variety of articles were searched for in order to include unpublished or non-commercial works in the analysis. Since studies can be available to the public in different forms, even though they are not yet published, several types of works were considered: conference papers, manuscripts, posters or presentations, theses/dissertations, books chapters, transcripts, and reports. Also, papers were searched in bibliographic lists or among those that cite articles already selected. In addition, authors that studied Internet use-SCC relationship were contacted through e-mail and asked if they know about further studies. Lastly, a search has been made on the "Open Grey" website, for gray literature.

For articles included in meta-analysis, publication bias was tested with the Comprehensive Meta-Analysis (Version 2.0; Borenstein et al., 2005), using both Egger's regression test and Duval and Tweedie's test.

\section{Results}

\section{Study Selection}

The steps of identifying articles are detailed in the PRISMA flow diagram (Moher et al., 2009) in Figure 1. After removing duplicates, 2,598 studies were evaluated according to title and abstract information, out of which 2,541 (97.80\%) were excluded.

The increased number of excluded articles is not unusual, as it was observed that over $90 \%$ of the studies identified in primary searches for systematic reviews usually are not eligible for inclusion (Majd et al., 2015). In the present study the main reason for exclusion based on title and abstract was the irrelevance to the theme. For example, in many articles the term "Internet" did not refer to a variable in the research, but to the fact that participants had to complete online surveys or that research announcements were posted on different sites. Moreover, the term "clarity" did not always refer to SCC.

Fifty-eight full-text articles were assessed, 39 being excluded on reasons detailed in Figure 1. Thus, 19 studies met the eligibility criteria for qualitative synthesis, and eight were also included in meta-analysis. Some of the papers had several studies or more samples, which were treated independently, as already mentioned in a previous section. Thus, the qualitative analysis implied a total of 21 studies, and the quantitative analysis totaled 11 studies. 
Figure 1. PRISMA Flow Diagram Illustrating the Process of Identifying the Articles.
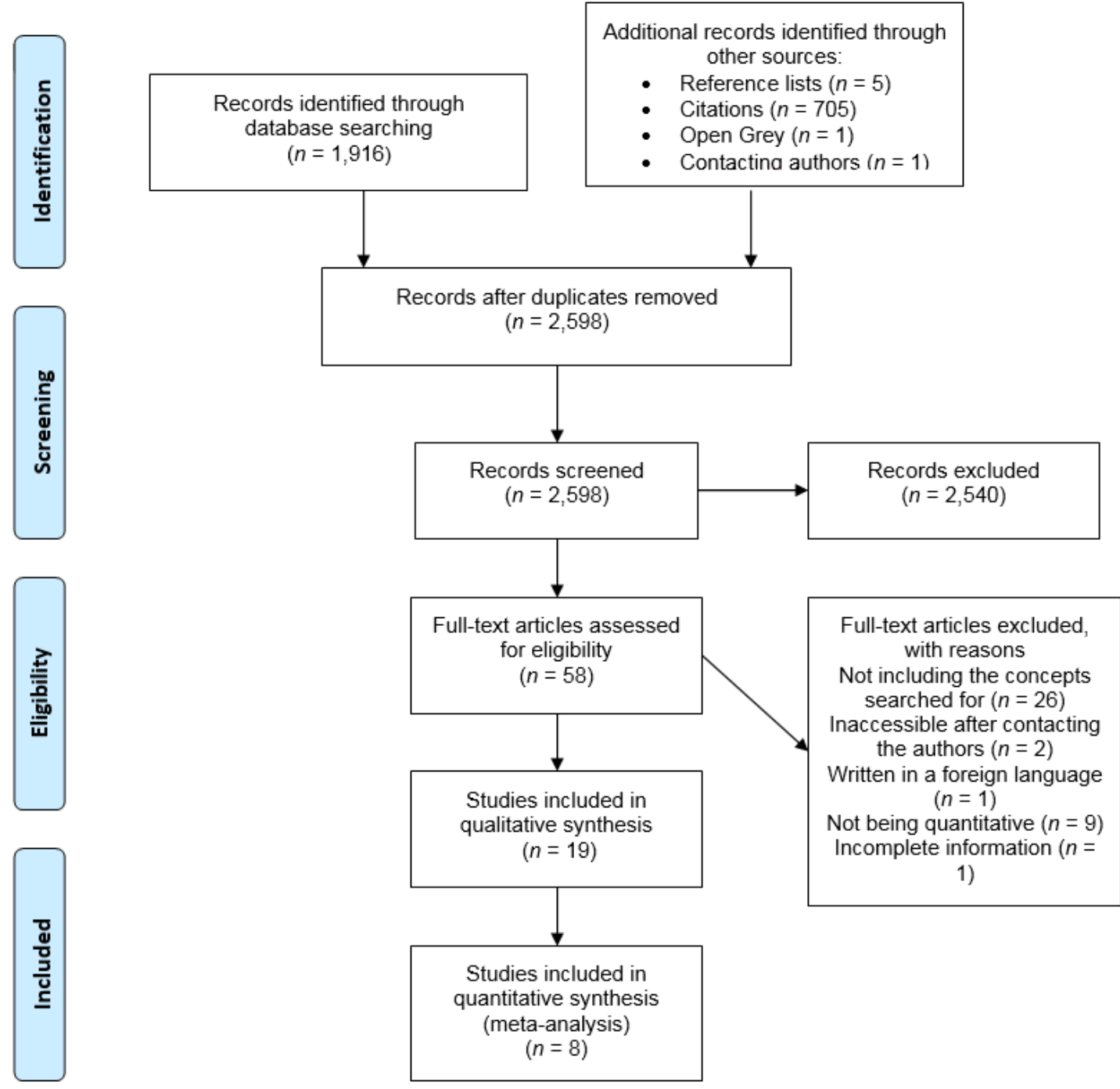

Studies included in quantitative synthesis (meta-analysis) $(n=8)$

\section{Studies' Characteristics}

The characteristics of each study were synthesized in Table S1.

Most of the studies $(n=18)$, meaning 85.71\%, were published between 2012 and 2018.

Studies were published in different countries, as follows: China $(n=1)$, Greece $(n=1)$, Malaysia $(n=1)$, New Zealand $(n=1)$, The United States of America $(n=4)$, the United Kingdom $(n=3)$, Croatia $(n=1)$, Canada $(n=1)$. Three of the studies had participants from several countries.

In terms of study design, only two of them involved a longitudinal design and only one had an experimental design. The remaining $85.71 \%$ of studies $(n=18)$ were performed with a cross-sectional design. Of the selected studies, six tested a mediation model, although the design was cross-sectional. Just one study tested a mediation model on a design that involved two measurement moments.

On average, the sample size was of 424.28 participants, with a minimum of 12 and a maximum of 2,079. Overall, the number of participants for the systematic review was 8,910, while for the meta-analysis it was 3,298.

Most studies ( $n=15$ ) included participants under the age of 30, focusing on adolescence and emerging adulthood. Six studies included people over 30 years of age.

All studies defined SCC in the same way, namely in accordance to Campbell's (1990) definition. In two of them, however, SCC was termed "self-concept unity" and "confused identity", and in another study it was characterized 
as one of the dimensions of "self-uncertainty". Despite the different terminology, the concept has been defined and operationalized in the same way. In terms of the Internet, several issues have been studied, which are described in Table 1. One study explicitly considered online games, nine referred to the Internet in general and nine studied aspects of social networking, of which Facebook was the most popular $(n=6)$.

Table 1. Internet Operationalization Across Studies.

\begin{tabular}{|c|c|c|}
\hline $\begin{array}{l}\text { Internet } \\
\text { operationalization }\end{array}$ & $n$ & Description \\
\hline $\begin{array}{l}\text { Online impression } \\
\text { management }\end{array}$ & 4 & $\begin{array}{l}\text { Veracity of self-presentation on the Internet (e.g., real, ideal or false self), online } \\
\text { presentation of multiple selves, the degree of self-disclosure }\end{array}$ \\
\hline Use of Internet & 6 & Time spent online, Internet access frequency \\
\hline Intensity of Internet use & 7 & $\begin{array}{l}\text { The degree of emotional connection with Internet sites, like Facebook, and how much they } \\
\text { are integrated in daily life }\end{array}$ \\
\hline Compulsive Internet use & 2 & $\begin{array}{l}\text { Withdrawal symptoms (e.g., negative emotions when the activity is interrupted), behavioral } \\
\text { symptoms (e.g., the behavior is dominated by the activity), relapse, control loss, } \\
\text { interpersonal conflicts }\end{array}$ \\
\hline Internet addiction & 3 & Emotional, cognitive, physiological and behavioral aspects of Internet use \\
\hline $\begin{array}{l}\text { Preference of virtual } \\
\text { interactions }\end{array}$ & 2 & Preference for online support/ interaction to the detriment of face to face interaction \\
\hline $\begin{array}{l}\text { Online interaction and } \\
\text { its quality }\end{array}$ & 6 & $\begin{array}{l}\text { The motivation for connecting with new/ already known people, positive/ negative } \\
\text { emotions following online interaction, number of Facebook friends, feedbacks received } \\
\text { from friends, social comparison, diversity of communication partners } \\
\text { Information, interpersonal communication, entertainment }\end{array}$ \\
\hline Internet motivation & 2 & $\begin{array}{l}\text { Online gaming motivation: social motifs, escape, competition, coping, ability development, } \\
\text { fantasy e.g., be someone else), recreation }\end{array}$ \\
\hline $\begin{array}{l}\text { Active or passive } \\
\text { Internet use }\end{array}$ & 2 & $\begin{array}{l}\text { The degree a person contributes actively to the Internet content (e.g., by posing comments, } \\
\text { images, texts etc.) }\end{array}$ \\
\hline $\begin{array}{l}\text { Types of Internet } \\
\text { activities }\end{array}$ & 5 & $\begin{array}{l}\text { Specific activities that can be done on different sites (e.g., changing profile photo, posting, } \\
\text { liking, commenting, texting others etc.) }\end{array}$ \\
\hline Identity exploration & 2 & $\begin{array}{l}\text { Expressing and exploring different aspects of personality, conducting identity experiments } \\
\text { (e.g., pretending to be someone else) }\end{array}$ \\
\hline $\begin{array}{l}\text { Impressions of Internet } \\
\text { users }\end{array}$ & 1 & $\begin{array}{l}\text { Internet/ Reality Incongruency: beliefs about the incongruence of others' self-presentation } \\
\text { on the Internet versus in reality } \\
\text { Global Negative Impressions: negative impressions of other Internet users } \\
\text { Global Positive Impressions: positive impressions of other Internet users }\end{array}$ \\
\hline
\end{tabular}

All the studies used self-report instruments. SCC was measured with the Self Concept Clarity Scale (Campbell et al., 1996), while the measures for Internet use varied as a function of the study's purpose. The most used measure for the Internet was Facebook Intensity Scale (Ellison et al., 2007). Generally, Cronbach alphas varied between 0.62 and 0.96. The questionnaires were given online $(n=12)$, in pencil paper form $(n=7)$ or both $(n=2)$. In $42.85 \%$ of studies, the participants received a reward, in the form of money, extra credits, or gift cards. In $11.11 \%$ of the situations, the participants had the chance to win it in a prize draw. Generally, the recruitment procedures were the same regardless of the existence of a reward: research announcements made in schools, universities, mental health clinics or on the Internet; snowball sampling method; e-mail messages sent to potential participants; direct approaching of the participants in public places.

\section{Study Quality Assessment}

A total score was obtained for each study, reflecting both the study quality and the risk of bias. Because some items did not apply to all studies, the score was calculated as the arithmetic mean of the points assigned to each item of the checklist (see Table S3). The mean of total scores was 2. $24(S D=0.28)$. Studies with a lower score than one standard deviation below average, meaning a score of 1.96, were considered poor quality studies, while one standard deviation above average (i.e., over a score of 2.53), meant high quality. Most of the studies presented acceptable quality, one had poor quality and two were high qualitative. The poor-quality study was not included in the meta-analysis, but it was considered for the systematic review.

One common observation was the lack of apriori estimation of the sample size. Also, several studies used crosssectional designs, even if this type of design was inappropriate for the tested hypothesis. In two studies, the 
psychometric features of the instruments were not mentioned and in one study there were no issues related to their cultural validity. Fourteen studies mention efforts to evaluate or improve the quality of the tools used. Less qualitative studies also showed difficulty in defining concepts.

\section{SCC and Internet Use: A Systematic Review}

\section{SCC and the General Use of Internet}

Approximately $60 \%$ of the included studies addressed the relationship between SCC and the general use of Internet or of certain sites. This general use included time spent online, the intensity of Internet use, its compulsive or pathological use, Internet dependence, or Internet Gaming Disorder (IGD).

Overall, the results indicated a negative association between the two variables: people with a less clear selfconcept tend to spend more time on the Internet. One hypothesis was that adolescents with low SCC make more use of the online environment in their desire to benefit from the rich information available and to increase selfclarification (Israelashvili et al., 2012) through self-exploration (Matsuba, 2006), experimentation of different roles and even through creating an avatar with a well-defined identity (Šporčić \& Glavak-Tkalić, 2018).

On the contrary, other authors (e.g., Appel et al., 2018) assumed that exposing the individual to a great variability in terms of self-expression, and feedback received from others, sites like Facebook prevent the formation of a consistent and stable self-concept. According to Sharif and Khanekharab (2017), the self-concept confusion may facilitate the development of materialism as an attempt to compensate for uncertainty through material objects and external gratifications. In this context, SCC and materialism mediated the relationship between excessive use of social networks and compulsive shopping online.

Another explanation could be that people with low SCC spend more time on the Internet as they prefer online interactions instead of face-to-face interactions (Quinones \& Kakabadse, 2015a, 2015b). According to Quinones and Kakabadse (2015b) self-confusion makes it difficult for the development of healthy relationships, as interactions imply knowing who you are so that you can exchange personal information. Consequently, as the online environment offers the opportunity to control self-presentation, including the conflicting aspects of the self-concept, such people may develop a preference for online interactions.

However, not all studies have highlighted the existence of a relationship between SCC and Internet use (e.g., Drogos, 2015). Most of the time, there was no association between time spent online and SCC, even if the latter correlated with Internet usage or Internet addiction (e.g., Israelashvili et al., 2012). On one hand, considering the positive association between SCC and self-esteem (e.g., Campbell et al., 1996), a person that self-reports a low SCC may also be likely to self-report problematic Internet use due to a tendency to self-evaluate more negatively. This would explain why SCC was associated with problematic use, but not with time on the Internet. On the other hand, time spent online is conceptually different from Internet usage, which comprises of also an emotional dimension (Drogos, 2015) or from Internet addiction, which also addresses emotional, cognitive, behavioral, physiological aspects (Israelashvili et al., 2012). Not the amount of time used in the online environment matters, but the purpose in which it is used (Israelashvili et al., 2012).

Most studies use concepts like "addiction" or "intensity", which imply more than a mere quantification of online time. In this context, several hypotheses have been put forward, all of which highlight the need to particularize the study of Internet use in relation to SCC.

\section{SCC and Qualitative Aspects of Using the Internet}

Some authors focused on qualitative aspects of Internet use, rather than quantitative, such as quality of online interactions (Daniels, 2014) and types of feedback (e.g., Yang \& Brown, 2016). Neither negative or positive feelings after Facebook interaction, nor supportive feedback from others did correlate with SCC (Daniels, 2014; Yang \& Brown, 2016). However, exploring the relationship between SCC and the feedback received by adolescents on Facebook, Drogos (2015) pointed out that it is the feedback's degree of consistency that is relevant to SCC, and not its positive or negative valence. The feedback about oneself is interpreted by adolescents as either congruent or 
inconsistent with their self-presentation. Appreciations can be easily classified as indicators of congruence, which strengthens the stability of the self-concept and this is why the number of likes turned out to be a positive predictor for SCC. Contradictory feedback diminishes the clarity of the self-concept. Comments can show a greater diversity, the same post having both commentaries that are in agreement and disagreement with self-representation and this is why the frequency of comments left on posts was a negative predictor for SCC.

\section{SCC and Internet Impression Management}

Another focus of the studies was on how users choose to present themselves on the Internet and whether this presentation relates to their self-concept. For example, SCC was negatively associated with the presentation of an ideal or false self (i.e., features the person would like to have or that are fictious, in contrast to the real ones), but positively with the expression of the real self (Adrianos, n.d.). Fullwood et al. (2016) reported that people with a less stable self-concept were more likely to show the world an ideal online self. The authors postulated that this may be the best way to get positive feedback when users are not sure how they would like to be seen by others.

In line with this idea, it was assumed that teenagers with a low SCC may be more inclined to explore alternative online identities as an attempt at self-discovery (Fullwood et al., 2016). However, identity experiments turned out not to be such a common activity on the Internet (e.g., Appel et al., 2018). Moreover, the negative association between SCC and identity experiments was no longer significant when considering the mediating role of the variety of communication partners, respectively anxiety and loneliness as antecedents for SCC (Valkenburg \& Peter, 2008).

Another explored aspect of how users present themselves was the intentionality of their self-disclosure. Even if intentional and conscious self-disclosure was associated with greater self-reflection, the latter correlated negatively with SCC, especially when reflecting on what to reveal came in the form of a ruminative process (Yang \& Brown, 2016).

Regarding impression management, it was also studied whether the way someone presented his or herself on Internet would change specific aspects in the self-concept. Lang (2012) conducted an experiment, where participants had to present themselves as risk-seekers. It was expected participants with high SCC to perceive themselves more as a risk seeker after the experiment, but the hypothesis was rejected. A possible explanation was that both self-presentation and self-concept were specific to a domain (risk seeking), while SCC was measured at a general level, so that the existing relationships could not be adequately captured.

\section{SCC and Other Types of Internet Activities}

Self-presentation is just one of the activities on the Internet. Researchers also investigated the relationship of SCC with other actions, such as social comparison. For example, when the self-concept is an uncertain one, Facebook users turn to social comparisons to enhance their self-concept (Lee, 2014). Thus, preadolescents engage in more aspect-related social comparisons when they have low SCC as they appeal to external sources to help them define their identity (Stafford-Bush, 2017). People with low SCC also use social comparison as an indicator for what ideal features to present in order to impress others (Adrianos, n.d.).

Apart from social comparison, the relation of SCC with specific online activities was also investigated, but the results were contradictory, ranging from positive to negative or null associations, depending on the focused activity. This can be explained by considering the type of Internet use (i.e., passive or active), which is defined by the user's contribution to the content of the site. In general, activities involving active engagement, such as posting photos, making comments and liking, correlated positively with SCC (e.g., Drogos, 2015; Stafford-Bush, 2017). For example, Drogos (2015) argued that deciding what photos to post online and in which to be labeled is a process of organizing self-perceptions, as it involves deciding what matches and what doesn't match one's self-perception. This process contributes, according to the author, to self-clarification.

Passive use (e.g., the observation of what others post, browsing and checking the reactions of others to one's posts, wasting time on Internet, downloading music) correlated negatively with SCC (e.g., Appel et al., 2018; Matsuba, 2006). In this respect, Lin and collaborators (2021) noted that people that were passively using the social 
networks were more likely to have a low SCC. This conclusion, according to the same authors, supports the fragmentation hypothesis, meaning that passive exposure to different opinions and values of different individuals would lead to uncertainty.

\section{SCC and Motivation to Use the Internet}

Matsuba (2006) highlighted that SCC correlated positively with the motivation to use the Internet for information and negatively with communication and entertainment purposes. According to the author, for young people with a lower SCC, the Internet was a tool that helped them experience more facets of the self and more roles in trying to find their identity. This was also confirmed by Davis (2013), who noted that adolescents with low SCC were motivated to express and explore aspects of identity on the Internet. Those who had a higher SCC, instead, used the Internet preponderantly to maintain their relationships with others.

Šporčić and Glavak-Tkalić (2018) identified motivations for playing online video games and studied them in relation to SCC and IGD. The only motivation that mediated the relationship between SCC and IGD was escapism. Specifically, people with low SCC used video gaming to escape from reality and to avoid the contact with oneself, which predisposed them to the development of IGD. Escaping from oneself was also outlined by the negative association of SCC with both coping motives (i.e., channeling distress and aggression, improving mood) and fantasy motives (i.e., trying new identities in a fantastic world and things users would not do in the real world).

\section{Intensity of the SCC and Internet Use Relationship: A Meta-Analysis}

Initially, meta-analysis included studies that considered the intensity of Internet use, Internet dependence, its pathological or compulsive use, and time spent online. The results highlighted a significant negative association between SCC and the use of the Internet: $r=-.329, \mathrm{Cl} 95 \%[-.43,-.21], p<.01$. However, studies proved a high degree of heterogeneity: over $91 \%$ of the dispersion being due to a real variation between them $(Q=115.696, d f$ $=10, p<.01, l^{2}=91.357$ ). As it can be seen from the systematic review, operationalizing "Internet use" as "number of hours spent online" is quite different from "Internet intensity" or "Internet dependence", which involved other dimensions as well. Moreover, the difference between them is also reflected in the direction of the relationship with SCC. For this reason, it was decided to exclude from the analysis outcomes regarding "number of hours spent online".

Repeating the analysis, the following results were obtained: $r=-.35, \mathrm{Cl} 95 \%[-.44,-.24], p<.01$ (see Table S4). Figure 2 presents the statistics for each study. Even so, studies proved a high degree of heterogeneity $(Q=101.409, d f=$ $\left.120, l^{2}=90.139, p<.01\right)$, so several moderators were tested.

Figure 2. Statistics for Each Study.

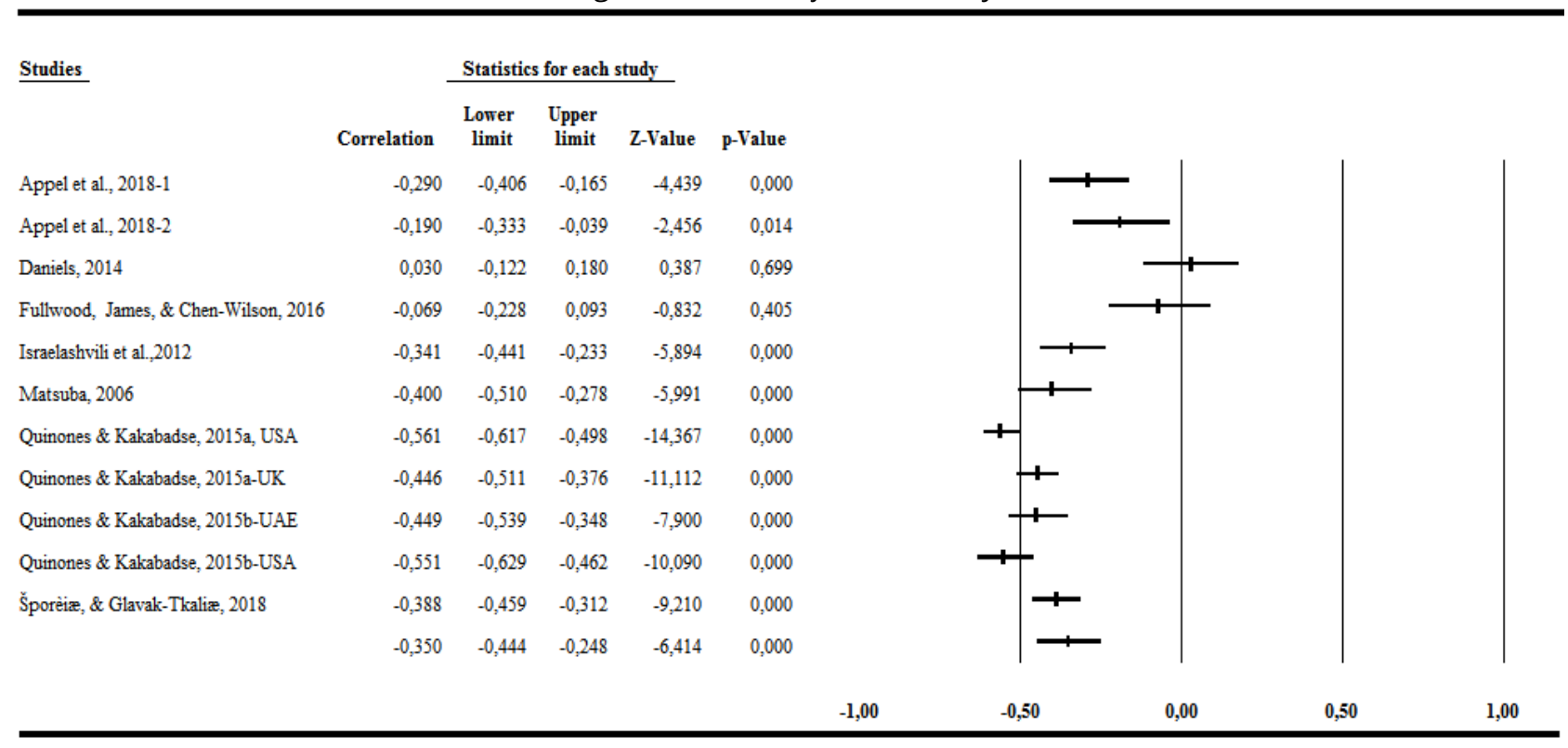




\section{Analysis of Moderators}

Results are presented in Table S5. One of the moderators was cultural background, which was described as a categorical variable on three levels: Europe, Asia and America. The cultural environment contributed to the heterogeneity of studies $(Q=10,441, d f=2, p=.005)$, the association between SCC and Internet use being higher for studies conducted on the American continent.

Internet operationalization was another moderator considered. In the end, the categorical moderator had three levels: intensity of Facebook usage, Internet addiction (dependence) and compulsive use of the Internet. Significant intergroup heterogeneity was found, confirming the moderating role of Internet operationalization $(Q=21.541, d f$ $=2, p<.01)$. A greater association was found between SCC and the compulsive use of the Internet.

Another moderator was the reward that the participants received or lack thereof $(Q=3.957, d f=1, p=.04)$, the associations being stronger for non-rewarded participants.

Part of the heterogeneity between studies was also explained by the sample composition, a moderator which was emphasized by the systematic review. Specifically, studies that included more heterogeneous samples in terms of age reported greater associations between variables of interest than those with narrower age ranges $(Q=10.992$, $d f=1, p=.001)$, as can be seen in Table S5. Studies not reporting the age range $(n=1)$ were excluded from the analysis. Next, differences between studies were explored according to the age category. A moderator variable with two levels was created: participants between 10-18 years of age and between 18-65 years of age. Studies with participants aged not in the two intervals (e.g., with ages between 14-20) were excluded $(n=2)$. The results pointed out that age category did not contribute to heterogeneity between studies $(Q=1.932, d f=1, p=.16)$.

Neither the volume of the sample $(Q=13.939, d f=12, p=.30)$ nor the quality of the studies $(Q=10.781, d f=10, p$ $=.37$ ) did contribute to this heterogeneity (see Table S6).

\section{Publication Bias}

Egger's test outlined a risk for publication bias $(t=3.026, d f=9, p=.01)$. However, the result should be interpreted cautiously, given the small number of studies included, which diminishes the precision of the bias risk estimate (Sterne et al., 2011). Using the method of Duval and Tweedie, a value of $-0.39, \mathrm{Cl} 95 \%$ [-0.443; -0.248$]$ was obtained. Values remained unchanged following the adjustment, suggesting that the included studies are equally distributed across both sides of the overall effect.

\section{Discussion}

This paper aimed to synthesize the conclusions of studies that investigated the relationship between SCC and the use of Internet. In 2011, Valkenburg and Peter identified only three studies to address this relationship and their results were contradictory. Some argued that online environment allowed for a process of clarification of the selfconcept ("self-concept unity hypothesis"), while others claimed that Internet use impeded the development of a coherent and stable self-concept ("self-concept fragmentation hypothesis"). Nevertheless, some argued that there was actually no relationship between SCC and the use of the Internet. Since then, new studies have been published, highlighting the complexity of this issue.

\section{Empirical Evidence Brought in Support of Each Hypothesis}

\section{The Directionality of the Relationship Between the Two Variables}

Many studies (85.71\%) used a cross-sectional design which means that, irrespective of the interpretation of the results, the directionality of the relationship between SCC and the online environment remains uncertain. For instance, six of the studies tested a mediational model. Even if mediation was theoretically grounded, this was not enough to confirm the proposed model. Studies rather presented a certain probability of the model to exist in reality. 
Of the three studies addressing a different design, only study 3 in the broader research of Appel et al. (2018) proved to be relevant for the directionality of the relationship between SCC and Internet use. Their result supported the fragmentation hypothesis, the authors demonstrating how, over time, more intense use of Facebook predicted a lower SCC. Instead, SCC was not a predictor for using Facebook over time.

In conclusion, it is difficult to say which of the hypotheses is the right one, as the studies' designs did not allow a rigorous investigation of the relationship between SCC and the use of Internet. The only hypothesis somewhat empirically supported would be the self-concept fragmentation hypothesis. Even so, its generalizability is low since it was confirmed by only one study. Moreover, the study in question could not draw causal conclusions, as there was no experimental manipulation of the variables.

\section{The Quality of Evidence Brought in Support of Each Hypothesis}

Most studies brought evidence for a negative association between the use of online media and SCC, but how reliable is this evidence? In general, studies were of medium quality, but three proved to be of poor quality, resulting in additional caution when considering the results. For example, one study had a sample of 12 participants, which considerably reduces both the power of research to detect an effect and the possibility of generalizing the outcome. In addition, relatively few studies $(n=3)$ carried out apriori analysis to determine the sample size required, so it is unclear whether the number of participants could have influenced the detection of a significant effect, both in a positive and in a negative sense.

Another aspect that should be taken into account is that studies used self-report measures. On the one hand, their use was justified by the measured concept. Aspects such as attitudes, emotions, time spent online are best captured by the person himself/herself. On the other hand, responses could have been affected by social desirability. For example, to explore whether participants engage in online identity experiments, some researchers (e.g., Valkenburg \& Peter, 2008) used questions that investigated the extent to which they pretended to be someone else on the Internet. Such behaviors can, however, be regarded as socially undesirable, so many participants could have given a false response to put themselves in a more favorable light.

\section{Aspects of Internet Use Associated With SCC}

Traditionally, the hypotheses about the relationship between SCC and the use of Internet involved the idea of experimenting in the online media, which was not always the case. Valkenburg and Peter (2008) operationalized online experiments as the frequency with which adolescents pretended to be someone else when they communicated online. However, only $18 \%$ of adolescents admitted having experimented with their identity, although over half of them reported poor SCC levels. Similarly, Appel et al. (2018) pointed out that identity experimentation was a rare activity among young people. These experiments were also linked with the presentation of an ideal or a false self, but such self-presentations were less common than the presentation of the real self (e.g., Fullwood et al., 2016).

These observations could be explained in two ways. On the one hand, as already pointed out, participants may not admit involving in such experiments due to social desirability. On the other hand, I argue the self-concept fragmentation/unity hypothesis could go beyond the idea of experimenting with identity. SCC has been associated with activities that do not necessarily involve identity experiments, such as the nature of the feedback received, the passive use of Internet or online social comparison (e.g., Lee, 2014). In this context, while SCC was operationalized likewise throughout the studies, the Internet was operationalized in many different ways. Each operationalization had a different impact on the nature of Internet use-SCC relationship.

Some of the studies focused on a more general use of the online environment (i.e., time spent online, the intensity of Internet use, its compulsive or pathological use, Internet addiction, IGD), which, in most cases, was negatively associated with SCC. Among the explanations, both the self-concept fragmentation hypothesis (e.g., Appel et al., 2018; Sharif \& Khanekharab, 2017) and the self-concept unity hypothesis (Israelashvili et al., 2012; Šporčić \& Glavak-Tkalić, 2018) were mentioned. However, in some cases, SCC and Internet use did not correlate, especially when the latter has been quantified through time spent online (e.g., Drogos, 2015). Analyzing these cases, it was 
concluded that the purpose for using the Internet was more significant than the time spent online (Israelashvili et al., 2012).

Indeed, a deeper investigation into more precise elements of Internet use highlighted more diverse results, which added complexity to the nature of the Internet use-SCC relationship. For example, it was suggested that not the valence of feedback on social networks was important to SCC, but its degree of consistency. Thus, the frequency of "likes" correlated positively with SCC because they implied congruence, while the frequency of comments correlated negatively with SCC because they were more diverse and contradictory (Drogos, 2015).

Not all activities on the Internet were associated with SCC in the same way (Appel et al., 2018). Active use of the online environment, such as photo postings, liking or commenting, correlated positively with SCC (e.g., Drogos, 2015). However, passive use of the online environment, the observation of what others post, correlated negatively with SCC (e.g., Matsuba, 2006). These conclusions can suggest a clearer image on the difference between active and ruminative exploration of identity. An active use of the Internet involves attempts to affirm one's own identity and, depending on the feedback received, the person can better define who he/she wants to be. Passive use of the Internet, however, makes the person an observer of the online content. I argue that the simple observation of the extensive range of opinions and values existing on the Internet, without undertaking any action, is what makes them difficult to be synthesized in one's self-concept, identity exploration becoming a ruminative one.

The complexity of the relationship between SCC and Internet use was also highlighted by the motivation to use the Internet. Thus, people with high SCC used Internet to acquire new information or to connect with offline friends (Davis, 2013; Matsuba, 2006). Instead, people with low SCC were more motivated to use online games as an escape from their real, but uncertain self (Šporčić \& Glavak-Tkalić, 2018).

In conclusion, the association between SCC and Internet use is not a simple one when considering the multiple dimensions of the latter.

\section{Intensity of the Relationship Between SCC and Internet Use}

Most of the results supported the existence of a relationship between SCC and Internet use, but how strong was this association? A meta-analysis was conducted to answer this question. As the study of Internet use is so varied, the meta-analysis used those operationalizations that were repeated most often in studies. This common element was the quantification of the general use of Internet: the intensity of Facebook use, the compulsive and pathological use of Internet, Internet addiction and IGD. The identified overall effect was statistically significant, suggesting that there is indeed an association between SCC and Internet. However, studies proved high heterogeneity.

\section{Study Heterogeneity}

In spite of the efforts to include in the meta-analysis homogeneous studies, statistical analysis revealed significant heterogeneity between them. In order to explain it, several possible moderating variables were considered.

\section{Moderators}

The studies' quality and sample size were not significant moderators. An explanation would be that the studies included in the meta-analysis were qualitatively similar and didn `t differ much in terms of sample size.

Cultural background instead was found to be a significant moderator. Namely, the association between SCC and Internet usage was stronger for American samples. The result is not surprising considering that SCC refers to stability and coherence across time and situations, which are also the defining characteristics of the self in Western societies (Campbell et al., 1996). This means self-concept incongruities are more threatening for American population than for less individualistic societies, where the self is more flexible and socially dependent (Quinones \& Kakabadse, 2015a). Consequently, in individualistic cultures it's much more common to use Internet for increasing SCC or for compensating an incongruent real self. Therefore, it is imaginable that the relationship between SCC and Internet use would be stronger in the American population. 
Another moderator considered was the operationalization of Internet (i.e., Internet compulsive use, Internet dependence, intensity of Internet use), which proved to explain some of the heterogeneity between studies. The strongest association was between SCC and compulsive use of the Internet. Dependence, although conceptually overlapping with compulsive use, includes, besides dimensions of compulsivity (i.e., control loss, interpersonal conflicts, withdrawal, behavioral salience) also dimensions of involvement (i.e., tolerance, cognitive concern, euphoria), which are not associated with the negative consequences encountered in compulsive use (Quinones \& Kakabadse, 2015a). In other words, compulsive use is conceptualized more restrictively than dependence (Quinones \& Kakabadse, 2015b). Including aspects that do not necessarily have negative implications, the negative association between SCC and dependence was lower than in the case of compulsive Internet use. The intensity of Internet use generally referred to Facebook and it outlined the frequency and the duration of use, attachment to the site and its integration into everyday life (Ellison et al., 2007). Unlike the other two variables, intense use of the Internet correlated the least with SCC. It's possible that the intensity of Internet use emphasizes more its importance to the user and less a compulsive or a pathological engagement. In addition, generally referring to Facebook, this operationalization is more restrictive. Concluding, the results suggest that a low SCC is associated with an addictive use of the Internet, which can be seen as a safer space for social interaction (Quinones \& Kakabadse, 2015a), as a source for self-clarification or as a space to escape (Šporčić \& Glavak-Tkalić, 2018).

Another moderator considered was the presence of a reward as a result of participants' involvement in the research. A stronger association between SCC and Internet use was revealed for those who were not rewarded. Previous research has shown that study volunteers were more self-determinated (Sharp et al., 2006). This means volunteers needing to clarify their self-concept would be more driven to act toward their goal, by using the Internet, among other things. This would explain why the relationship between SCC and Internet use was stronger for volunteer participants.

Following the narrative synthesis, it was observed that some samples included a larger age range than others. Taking into account that SCC increases with age (Lodi-Smith \& Roberts, 2010), it was examined whether a greater age diversity in the sample influenced the relationship between SCC and Internet use. The result highlighted a weaker intensity of the relationship in studies with a narrower age range. In these studies the samples were made of adolescents or emerging adults- the main Internet users (Eurostat, 2016). As they are more accustomed to using online resources than the other age groups, differences in patterns of Internet usage may be less evident compared to more heterogenous groups. Similarly, as SCC is changing with time, one can expect differences in SCC to be greater in aged diverse samples. In other words, a larger age range captures more forms of manifestation of the studied phenomena, which can facilitate the detection of a stronger effect. Nonetheless, such heterogenous age groups might also present an increased risk for confounded variables.

The analysis of the age category (under 18 years of age, over 18 years of age), was somewhat in line with the above ideas. Although these categories did not explain the heterogeneity between studies, a less intensive relationship was observed for studies with participants under 18 years of age, who are more accustomed to using Internet. However, this result may also be due to the much smaller number of studies that had participants under 18 years of age than those with participants over 18 years of age.

\section{Limits and Strengths}

A limit of the meta-analysis was the studies' heterogeneity, which diminished comparability between studies. Although several moderators were considered to explain the variation of individual results, there may be other variables explaining some of this heterogeneity. For example, the meta-analysis considered the quality of the studies as a whole, but a more specific aspect, such as the quality of the measuring instruments, may matter more in explaining the variance. However, the same heterogeneity could be considered a strength for the systematic review as it provides a wider perspective and, implicitly, a better understanding of the relationship between SCC and the use of Internet.

Another limit was the risk of publication bias. Although precautions were taken to prevent it, the assessment of this risk suggested it was possible. If some unpublished or non-English studies, in particular, were omitted, then a publication bias is imaginable. However, the small number of studies included in the meta-analysis may have 
affected the outcome of the test, especially since the Duval and Tweedie method, subsequently applied, did not confirm the publication bias.

Also, a limit of meta-analysis was the only inclusion of outcomes about general use of Internet. As noted in the systematic synthesis, the more particular aspects of Internet use played an important role in the intensity and nature of the relationship with SCC.

Not least, the small sample of studies reduces the generalizability of the conclusions drawn. Even if some aspects were resumed in several studies (e.g., internet intensity), others, like online gaming and SCC, were scarcely addressed. In other words, it was suggested an association between SCC and different dimensions of the Internet use, but there is an additional need to explore the ideas outlined.

A merit of this research is that of identifying some of the gaps in the study of the relationship between SCC and Internet use. Specifically, there is a lack of longitudinal or experimental studies that could improve the understanding of this relationship. This research also deepens the understanding of the contradictory results regarding the relationship between SCC and Internet, emphasizing the importance of considering particular aspects of the Internet use. But studies that address Internet use in detail are also scarce. Aspects such as congruence in feedback, online experiments and passive Internet use should be further considered in order to confirm the few conclusions drawn upon them and to explore the mechanisms behind them. Moreover, few studies take into account periods of life, other than adolescence and youth, which makes it difficult to compare the results by age.

\section{Implications}

The review outlined the need for further studies addressing in more detail the Internet use-SCC relationship. So far, the conclusions indicate that Internet use is linked with SCC in many ways and their association can be both positive and negative. This conclusion has important practical implications in the controversy about the diagnostic criteria for IGD, which emphasizes the difficulty to delimit between normal, excessive and pathological use of Internet (Kuss et al., 2017). Understanding what is problematic in using the online environment can help specialists in making this delimitation. For example, the study review outlined that time spent online is not the core problem. Instead, compulsive use, escape motivation, false self-presentation or passive use can be detrimental to the individual, and to their SCC. At the same time, self-expressing on the Internet and maintaining social-relationships that could confirm one's self-concept can be positively associated with SCC. In this context, specialists should not focus only on the time spent online, but also on specific patterns of Internet use, both in clinical practice and in research elaboration.

\section{Generalizability}

As most of the study participants were teenagers or emerging adults, the results of this paper apply more to these age groups.

\section{Conclusions}

The main objective of this research was to explore the extent to which the three hypotheses regarding the relationship between SCC and the use of Internet were supported by empirical data. On the one hand, neither hypothesis was strongly supported, as the design of the studies, generally, did not allow the exploration of causality or directionality. Thus, although studies seemed to support one hypothesis or another, the arguments were theoretical rather than empirical. On the other hand, the observed results suggested that all assumptions are likely. The associations between SCC and Internet use differed depending on the type of online activities considered or the motivation behind them. In this situation, some of them would correlate positively with SCC, others negatively, while others would not correlate at all. The need to study particular aspects of the Internet, and not only the duration of its use, was also evidenced by meta-analysis. The meta-analysis highlighted the existence of several moderators that can affect the relationship between SCC and the Internet use. 


\section{Acknowledgement}

I would like to thank Simona Luiza Seteanu for her involvement in the assessment of studies' quality and Alina Olteanu for her help with the articles' screening. For guidelines and suggestions, I would like to thank Dr. Nicolae Mitrofan, Dr. Lucian Alecu, Dr. Adrian Luca, Dr. Ovidiu Pop, Ana Cosmoiu and Alexandra Moraru.

\section{References}

References marked with an asterisk indicate studies included in the meta-analysis.

*Adrianos, M. (n.d.). Real, ideal and false self-portraits: Examining the relationship between self-concept clarity and self presentation on Facebook. Unpublished manuscript.

*Appel, M., Schreiner, C., Weber, S., Mara, M., \& Gnambs, T. (2018). Intensity of Facebook use is associated with lower self-concept clarity: Cross-sectional and longitudinal evidence. Journal of Media Psychology, 30(3), 160-172. https://doi.org/10.1027/1864-1105/a000192

Bechtoldt, M. N., De Dreu, C. K. W., Nijstad, B. A., \& Zapf, D. (2010). Self-concept clarity and the management of social conflict. Journal of Personality, 78(2), 539-574. https://doi.org/10.1111/j.1467-6494.2010.00626.x

Borca, G., Bina, M., Keller, P. S., Gilbert, L. R., \& Begotti, T. (2015). Internet use and developmental tasks: Adolescents' point of view. Computers in Human Behavior, 52, 49-58. https://doi.org/10.1016/j.chb.2015.05.029

Borenstein, M., Hedges, L., Higgins, J., \& Rothstein, H. (2005). Comprehensive Meta-Analysis (Version 2.0) [Computer software]. Biostat.

Campbell, J. D. (1990). Self-esteem and clarity of the self-concept. Journal of Personality and Social Psychology, 59(3), 538-549. https://doi.org/10.1037/0022-3514.59.3.538

Campbell, J. D., Trapnell, P. D., Heine, S. J., Katz, I. M., Lavallee, L. F., \& Lehman, D. R. (1996). Self-concept clarity: Measurement, personality correlates, and cultural boundaries. Journal of Personality and Social Psychology, 70(1), 141-156. https://doi.org/10.1037/0022-3514.70.1.141

Caplan, S. E. (2003). Preference for online social interaction: A theory of problematic Internet use and psychosocial wellbeing. Communication Research, 30(6), 625-648. https://doi.org/10.1177/0093650203257842

Choi, E. J., Taylor, M. J., Hong, S.-B., Kim, C., Kim, J.-W., McIntyre, R. S., \& Yi, S.-H. (2018). Gaming-addicted teens identify more with their cyber-self than their own self: Neural evidence. Psychiatry Research: Neuroimaging, 279, 51-59. https://doi.org/10.1016/j.pscychresns.2018.05.012

Cicero, D. C. (2018). Self-concept clarity and psychopathology. In J. Lodi-Smith \& K. G. Demarree (Eds.), Selfconcept clarity: Perspectives on assessment, research, and applications (pp. 219-242). Springer International Publishing.

Clement, J. (2019, July). Global digital population 2019. Statista. https://www.statista.com/statistics/617136/digitalpopulation-worldwide/

*Daniels, M. (2014). Facebook and depression in late adolescence: Intensity of use, quality of interactions, and the role of self-definition and identity [Doctoral dissertation, Royal Holloway, University of London]. Royal Holloway Digital Repository. http://digirep.rhul.ac.uk/items/bb6e5c71-2df1-9a28-e0ab-ccccaa2f9b99/1/

d'Astous, A., Maltais, J., \& Roberge, C. (1990). Compulsive buying tendencies of adolescent consumers. Advances in Consumer Research, 17, 306-312. 
Davila, J., Hershenberg, R., Feinstein, B. A., Gorman, K., Bhatia, V., \& Starr, L. R. (2012). Frequency and quality of social networking among young adults: associations with depressive symptoms, rumination, and corumination. Psychology of Popular Media Culture, 1(2), 72-86. https://doi.org/10.1037/a0027512

*Davis, K. (2013). Young people's digital lives: The impact of interpersonal relationships and digital media use on adolescents' sense of identity. Computers in Human Behavior, 29(6), 2281-2293.

https://doi.org/10.1016/j.chb.2013.05.022

Demetrovics, Z., Urbán, R., Nagygyörgy, K., Farkas, J., Zilahy, D., Mervó, B., Reindl, A., Ágoston, C., Kertész, A., \& Harmath, E. (2011). Why do you play? The development of the Motives for Online Gaming Questionnaire (MOGQ). Behavior Research Methods, 43(3), 814-825. https://doi.org/10.3758/s13428-011-0091-y

*Drogos, K. L. (2015). The relationship between adolescent identity formation and social network site use [Unpublished doctoral dissertation]. University of Illinois.

Dunlop, W. L. (2017). Situating self-concept clarity in the landscape of personality. In J. Lodi-Smith \& K. G. DeMarree (Eds.), Self-concept clarity: Perspectives on assessment, research, and applications (pp. 19-43). Springer International Publishing.

Ellison, N. B., Steinfield, C., \& Lampe, C. (2007). The benefits of Facebook "friends:" Social capital and college students use of online social network sites. Journal of Computer-Mediated Communication, 12(4), 1143-1168. https://doi.org/10.1111/j.1083-6101.2007.00367.x

Eurostat. (2016). File: People who used the internet on a daily basis, by age and by formal education. Eurostat: Statistics Explained. https://ec.europa.eu/eurostat/statistics-

explained/index.php?title=File:People_who_used_the_internet_on_a_daily_basis,_by_age_and_by_formal_educati on,_EU-28,_2016_(\%25_share)_BYIE18.png

*Fullwood, C., James, B. M., \& Chen-Wilson, C.-H. J. (2016). Self-concept clarity and online self-presentation in adolescents. Cyberpsychology, Behavior and Social Networking, 19(12), 716-720.

https://doi.org/10.1089/cyber.2015.0623

Gackenbach, J., \& von Stackelberg, H. (2007). Self online: Personality and demographic implications. In J. Gackenbach (Ed.), Psychology and the Internet: Intrapersonal, interpersonal and transpersonal implications (2nd ed., pp. 55-76). Academic Press.

Guegan, J., Moliner, P., \& Buisine, S. (2015). Why are online games so self-involving: A social identity analysis of massively multiplayer online role-playing games. European Journal of Social Psychology, 45(3), 349-355. https://doi.org/10.1002/ejsp.2103

Hertel, A. W. (2017). Sources of self-concept clarity. In J. Lodi-Smith \& K. G. DeMarree (Eds.), Self-concept clarity: Perspectives on assessment, research, and applications (pp. 43-67). Springer International Publishing.

*Israelashvili, M., Kim, T., \& Bukobza, G. (2012). Adolescents' over-use of the cyber world - Internet addiction or identity exploration? Journal of Adolescence, 35(2), 417-424. https://doi.org/10.1016/j.adolescence.2011.07.015

Kuss, D. J., Griffiths, M. D., \& Pontes, H. M. (2017). Chaos and confusion in DSM-5 diagnosis of Internet Gaming Disorder: Issues, concerns, and recommendations for clarity in the field. Journal of Behavioral Addictions, 6(2), 103-109. https://doi.org/10.1556/2006.5.2016.062

*Lang, G. (2012). Think twice before you post: The impact of online self-presentation on the self-concept [Doctoral dissertation, The City University of New York]. https://papers.ssrn.com/abstract=2122809

*Lee, S. Y. (2014). How do people compare themselves with others on social network sites?: The case of Facebook. Computers in Human Behavior, 32, 253-260. https://doi.org/10.1016/j.chb.2013.12.009 
Lemmens, J. S., Valkenburg, P. M., \& Gentile, D. A. (2015). The Internet Gaming Disorder Scale. Psychological Assessment, 27(2), 567-582. https://doi.org/10.1037/pas0000062

*Lin, S., Liu, D., Liu, W., Hui, Q., Cortina, K. S., \& You, X. (2021). Mediating effects of self-concept clarity on the relationship between passive social network sites use and subjective well-being. Current Psychology, 40(3), 13481355. https://doi.org/10.1007/s12144-018-0066-6

Lodi-Smith, J., \& Roberts, B. W. (2010). Getting to know me: Social role experiences and age differences in selfconcept clarity during adulthood. Journal of Personality, 78(5), 1383-1410. https://doi.org/10.1111/j.14676494.2010.00655.x

Majd, N. M., Eghbal, M. J., Homayouni, H., \& Aflaki, S. (2015). The main reasons for excluding articles from systematic review and meta-analysis [Conference presentation]. Howard University Research Symposium 2015, Washington D. C., United States.

*Matsuba, M. K. (2006). Searching for self and relationships online. CyberPsychology \& Behavior, 9(3), 275-284. https://doi.org/10.1089/cpb.2006.9.275

Meerkerk, G., van den Eijnden, R. J. J. M., Franken, I. H. A. \& Garretsen, H. F. L. (2010). Is compulsive Internet use related to sensitivity to reward and punishment, and impulsivity? Computers in Human Behavior, 26(4), 729-735. https://doi.org/10.1016/j.chb.2010.01.009

Michikyan, M., Subrahmanyam, K., \& Dennis, J. (2014). Can you tell who I am? Neuroticism, extraversion, and online self-presentation among young adults. Computers in Human Behavior, 33, 179-183.

https://doi.org/10.1016/j.chb.2014.01.010

Moher, D., Liberati, A., Tetzlaff, J., Altman, D. G., \& The PRISMA Group. (2009). Preferred reporting items for systematic reviews and meta-analyses: The PRISMA statement. Journal of Clinical Epidemiology, 62(10), 10061012. https://doi.org/10.1016/j.jclinepi.2009.06.005

Moola, S., Munn, Z., Tufanaru, C., Aromataris, E., Sears, K., Sfetc, R., Currie, M., Lisy, K., Qureshi, R., Mattis, P., \& Mu, P.-F. (2017). Systematic reviews of etiology and risk. In E. Aromataris \& Z. Munn (Eds.), JBI Manual for Evidence Synthesis. The Joanna Briggs Institute.

Morahan-Martin, J., \& Schumacher, P. (2000). Incidence and correlates of pathological Internet use among college students. Computers in Human Behavior, 16(1), 13-29. https://doi.org/10.1016/S0747-5632(99)00049-7

Mueller, A., Mitchell, J. E., Peterson, L. A., Faber, R. J., Steffen, K. J., Crosby, R. D., \& Claes, L. (2011). Depression, materialism, and excessive Internet use in relation to compulsive buying. Comprehensive Psychiatry, 52(4), 420424. https://doi.org/10.1016/j.comppsych.2010.09.001

Palfrey, J., \& Gasser, U. (2008). Born digital: Understanding the first generation of digital natives. Basic Books.

Pempek, T. A., Yermolayeva, Y. A., \& Calvert, S. L. (2009). College students' social networking experiences on Facebook. Journal of Applied Developmental Psychology, 30(3), 227-238.

https://doi.org/10.1016/j.appdev.2008.12.010

*Quinones, C., \& Kakabadse, N. K. (2015a). Self-concept clarity, social support, and compulsive Internet use: A study of the US and the UAE. Computers in Human Behavior, 44, 347-356.

https://doi.org/10.1016/j.chb.2014.11.019

*Quinones, C., \& Kakabadse, N. K. (2015b). Self-concept clarity and compulsive Internet use: The role of preference for virtual interactions and employment status in British and North-American samples. Journal of Behavioral Addictions, 4(4), 289-298. https://doi.org/10.1556/2006.4.2015.038 
Shapiro, L. A. S., \& Margolin, G. (2014). Growing up wired: Social networking sites and adolescent psychosocial development. Clinical Child and Family Psychology Review, 17(1), 1-18. https://doi.org/10.1007/s10567-013-0135-1

*Sharif, S. P., \& Khanekharab, J. (2017). Identity confusion and materialism mediate the relationship between excessive social network site usage and online compulsive buying. Cyberpsychology, Behavior and Social Networking, 20(8), 494-500. https://doi.org/10.1089/cyber.2017.0162

Sharp, E. C., Pelletier, L. G., \& Lévesque, C. (2006). The double-edged sword of rewards for participation in psychology experiments. Canadian Journal of Behavioural Science / Revue Canadienne Des Sciences Du Comportement, 38(3), 269-277. https://doi.org/10.1037/cjbs2006014

*Šporčić, B., \& Glavak-Tkalić, R. (2018). The relationship between online gaming motivation, self-concept clarity and tendency toward problematic gaming. Cyberpsychology: Journal of Psychosocial Research on Cyberspace, 12(1), Article 4. https://doi.org/10.5817/CP2018-1-4

*Stafford-Bush, T. (2017). Is it \#gramworthy?: An investigation of self-concept clarity, social media and body related issues and how this relates to teenage self presentation on Instagram [Master's thesis, Massey University]. http://hdl.handle.net/10179/11711

Steele, C. M. (1988). The psychology of self-affirmation: Sustaining the integrity of the self. Advances in Experimental Social Psychology, 21, 261-302. https://doi.org/10.1016/S0065-2601(08)60229-4

Sterne, J. A. C., Sutton, A. J., Ioannidis, J. P. A., Terrin, N., Jones, D. R., Lau, J., Carpenter, J., Rücker, G., Harbord, R. M., Schmid, C. H., Tetzlaff, J., Deeks, J. J., Peters, J., Macaskill, P., Schwarzer, G., Duval, S., Altman, D. G., Moher, D., \& Higgins, J. P. T. (2011). Recommendations for examining and interpreting funnel plot asymmetry in metaanalyses of randomised controlled trials. BMJ, 343, Article d4002. https://doi.org/10.1136/bmj.d4002

*Trask, C. L. (2020). Perceptions of other Internet users in delusional beliefs: Development and validation of a new measure of online social cognition [Unpublished doctoral dissertation]. University of Hawaii.

*Valkenburg, P. M., \& Peter, J. (2008). Adolescents' identity experiments on the Internet: Consequences for social competence and self-concept unity. Communication Research, 35(2), 208-231.

https://doi.org/10.1177/0093650207313164

Valkenburg, P. M., \& Peter, J. (2011). Online communication among adolescents: An integrated model of its attraction, opportunities, and risks. Journal of Adolescent Health, 48(2), 121-127.

https://doi.org/10.1016/j.jadohealth.2010.08.020

Van Dijk, M. P. A., Branje, S., Keijsers, L., Hawk, S. T., Hale, W. W., III. \& Meeus, W. (2014). Self-concept clarity across adolescence: Longitudinal associations with open communication with parents and internalizing symptoms. Journal of Youth and Adolescence, 43(11), 1861-1876. https://doi.org/10.1007/s10964-013-0055-X

Vandenbroucke, J. P., von Elm, E., Altman, D. G., Gøtzsche, P. C., Mulrow, C. D., Pocock, S. J., Poole, C., Schlesselman, J. J., \& Egger, M. (2007). Strengthening the Reporting of Observational Studies in Epidemiology (STROBE): Explanation and elaboration. Epidemiology, 18(6), 805-835.

https://doi.org/10.1097/EDE.0b013e3181577511

Vartanian, L. R., \& Dey, S. (2013). Self-concept clarity, thin-ideal internalization, and appearance-related social comparison as predictors of body dissatisfaction. Body Image, 10(4), 495-500.

https://doi.org/10.1016/j.bodyim.2013.05.004

Verduyn, P., Lee, D. S., Park, J., Shablack, H., Orvell, A., Bayer, J., Ybarra, O., Jonides, J., \& Kross, E. (2015). Passive Facebook usage undermines affective well-being: Experimental and longitudinal evidence. Journal of Experimental Psychology: General, 144(2), 480-488. https://doi.org/10.1037/xge0000057 
Wheeless, L. R. (1976). Self-disclosure and interpersonal solidarity: Measurement, validation, and relationships. Human Communication Research, 3(1), 47-61. https://doi.org/10.1111/j.1468-2958.1976.tb00503.x

Wheeless, L. R. (1978). A follow-up study of the relationships among trust, disclosure, and interpersonal solidarity. Human Communication Research, 4(2), 143-157. https://doi.org/10.1111/j.1468-2958.1978.tb00604.x

Wolfradt, U., \& Doll, J. (1999). Motives of adolescents to use the Internet as a function of personality traits, personal and social factors. Journal of Educational Computing Research, 24(1), 13-27.

https://doi.org/10.2190/ANPM-LN97-AUT2-D2EJ

*Yang, C.-c., \& Brown, B. B. (2016). Online self-presentation on Facebook and self development during the college transition. Journal of Youth and Adolescence, 45(2), 402-416. https://doi.org/10.1007/s10964-015-0385-y

Young, K. S. (1998). Internet addiction: The emergence of a new clinical disorder. CyberPsychology \& Behavior, 1(3), 237-244. https://doi.org/10.1089/cpb.1998.1.237 


\section{Appendix A}

Table S1. Main Characteristics of Studies Included in the Review Article "The Relationship between Internet Use and Self-Concept Clarity: Systematic Review and Meta-Analysis".

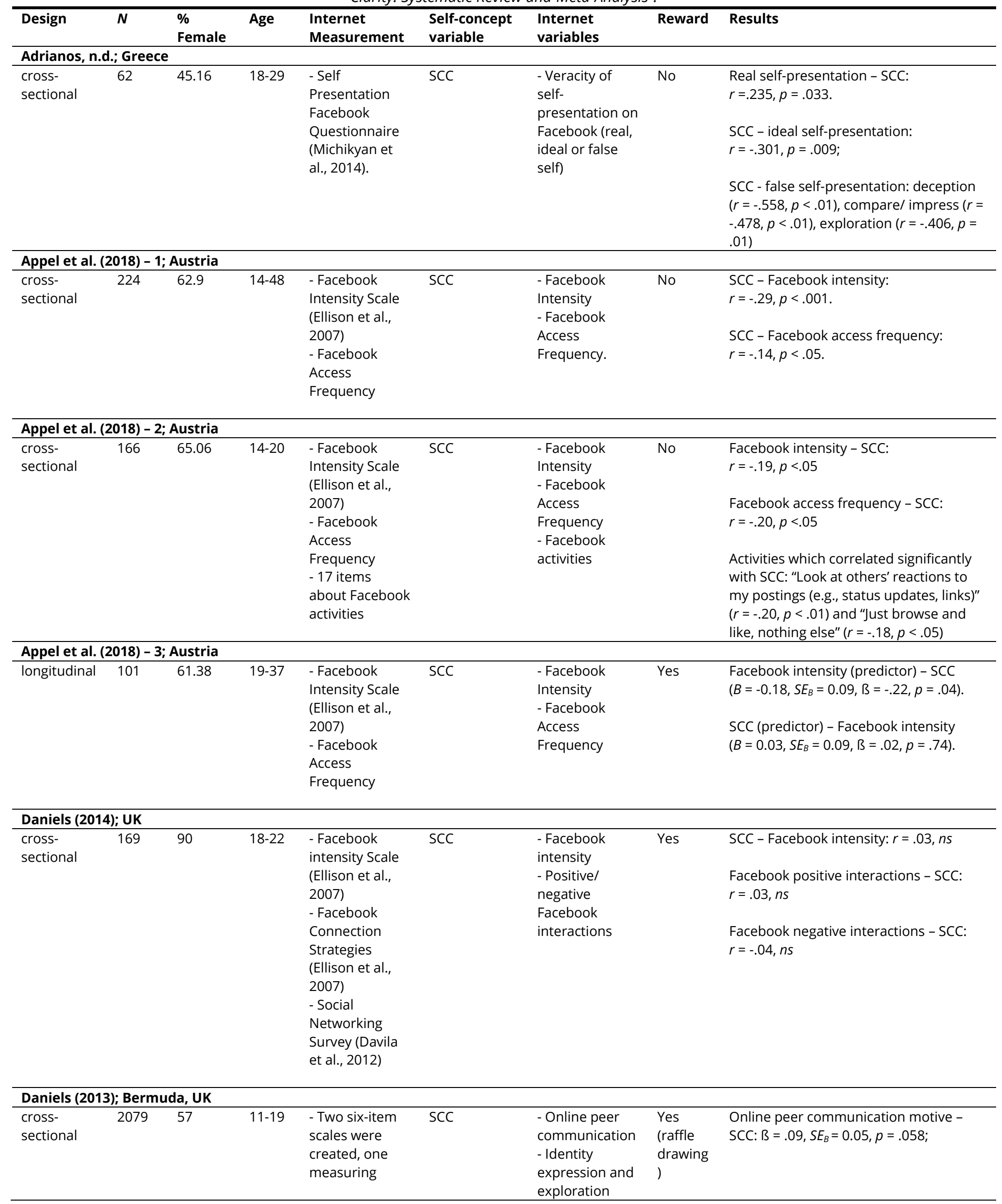


online peer

communication

and the other

measuring

online identity

expression and

exploration
Identity expression and exploration

motive - SCC:

$B=-.47, S E_{B}=0.04, p<.0001$;

Friendship quality totally mediated SCC online peer communication relationship: $z=4.63, p<.001$;

Friendship quality partially mediated SCC - identity exploration relationship: $z$ $=-4.29, p<.001$.

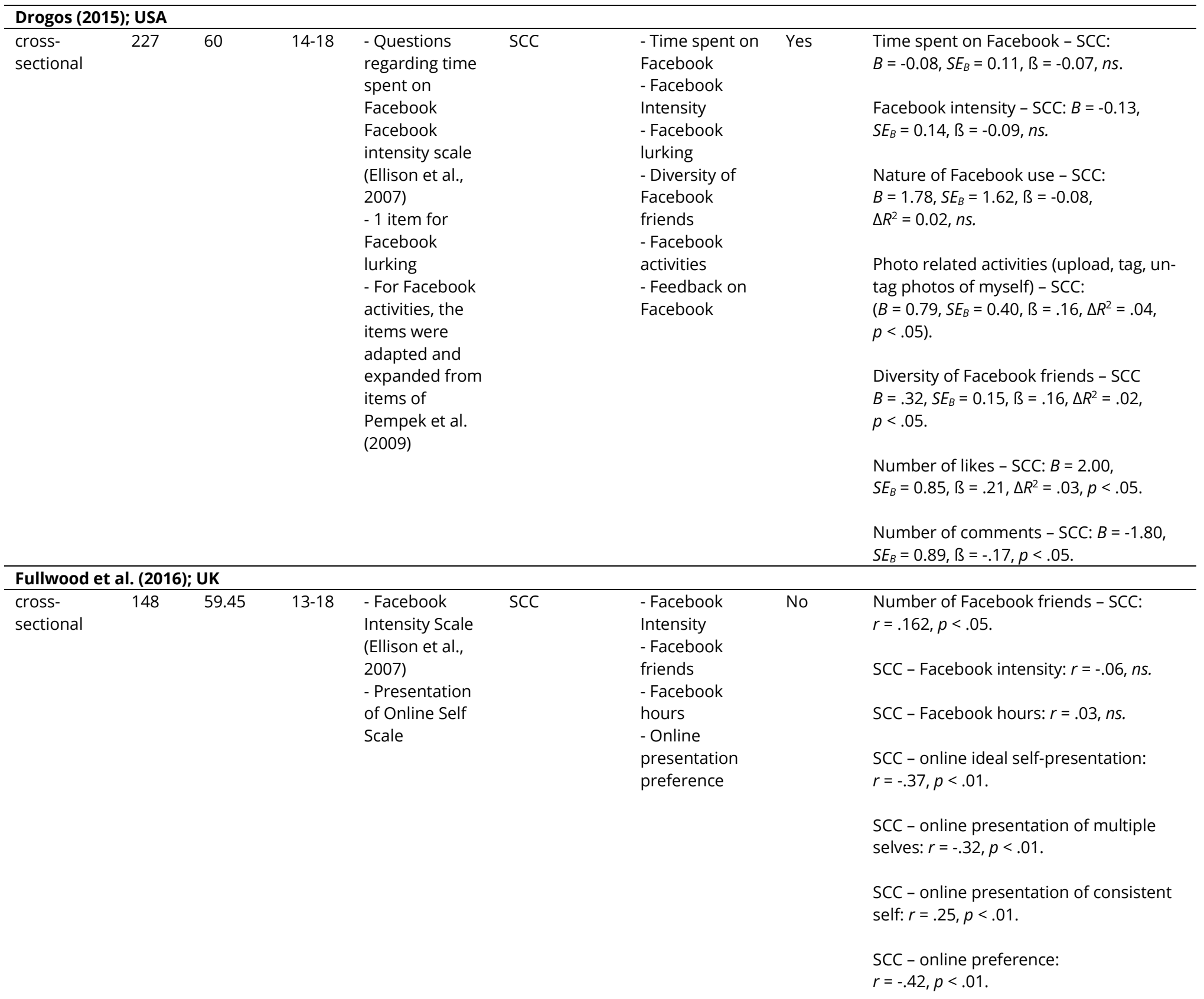

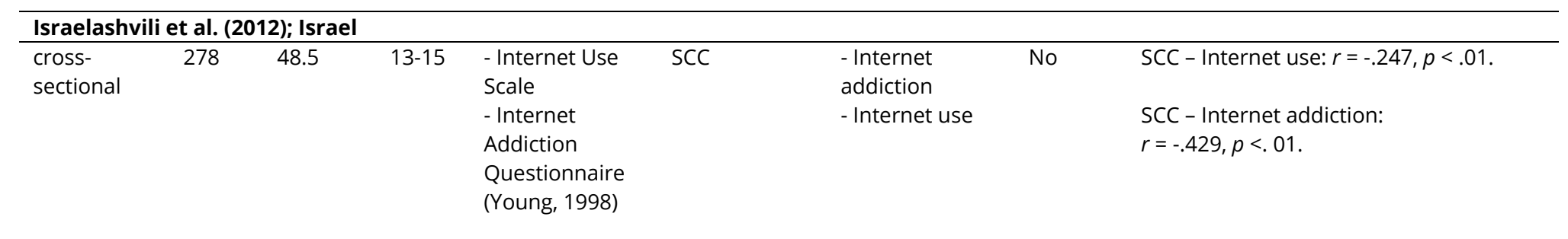




\begin{tabular}{|c|c|c|c|c|c|c|c|c|}
\hline $\begin{array}{l}\text { Experimen- } \\
\text { tal }\end{array}$ & 284 & 39.08 & $\begin{array}{l}\text { Over } \\
18\end{array}$ & $\begin{array}{l}\text { - Self- } \\
\text { presentation on } \\
\text { a site, } \\
\text { according to } \\
\text { given } \\
\text { instructions }\end{array}$ & SCC & $\begin{array}{l}\text { - Online self- } \\
\text { presentation }\end{array}$ & Yes & $\begin{array}{l}\text { SCC is not a moderator of online self- } \\
\text { presentation and self-concept } \\
\text { relationship }(p>0.10) \text {. } \\
\text { Online self-presentation - SCC: } r=.14 \text {. }\end{array}$ \\
\hline \multicolumn{9}{|c|}{ Lee (2014); USA } \\
\hline $\begin{array}{l}\text { cross- } \\
\text { sectional }\end{array}$ & 191 & 38 & $18-23$ & $\begin{array}{l}\text { - Facebook } \\
\text { Intensity Scale } \\
\text { (Ellison et al., } \\
\text { 2007) } \\
\text { - A question } \\
\text { about Facebook } \\
\text { social } \\
\text { comparison } \\
\text { frequency } \\
\text { - Questions } \\
\text { about the } \\
\text { frequency of } \\
\text { having a } \\
\text { negative feeling } \\
\text { from } \\
\text { comparison on } \\
\text { Facebook } \\
\text { - Questions } \\
\text { about number } \\
\text { of friends. }\end{array}$ & $\begin{array}{l}\text { Self- } \\
\text { uncertainty }\end{array}$ & $\begin{array}{l}\text { - Facebook } \\
\text { social } \\
\text { comparison } \\
\text { frequency } \\
\text { - Frequency of } \\
\text { having a } \\
\text { negative feeling } \\
\text { from } \\
\text { comparison on } \\
\text { Facebook }\end{array}$ & Yes & $\begin{array}{l}\text { SCC - Facebook social comparison } \\
\text { frequency: } r=-.54, p<.01 \text {. } \\
\text { SCC - frequency of having a negative } \\
\text { feeling from comparison on Facebook: } r \\
=-.54, p<.01 \text {. }\end{array}$ \\
\hline \multicolumn{9}{|c|}{ Lin et al. (2018); China } \\
\hline $\begin{array}{l}\text { cross- } \\
\text { sectional }\end{array}$ & 328 & 58.23 & $18-30$ & $\begin{array}{l}\text { - The Passive } \\
\text { SNS use } \\
\text { questionnaire } \\
\text { (Verduyn et al., } \\
\text { 2015) }\end{array}$ & SCC & $\begin{array}{l}\text { - Passive use of } \\
\text { SNS }\end{array}$ & No & $\begin{array}{l}\text { SCC - passive use of SNS: } \\
r=-.23, p<.001\end{array}$ \\
\hline \multicolumn{9}{|c|}{ Matsuba (2006); Canada } \\
\hline $\begin{array}{l}\text { cross- } \\
\text { sectional }\end{array}$ & 203 & 72 & $\begin{array}{l}M= \\
20.5\end{array}$ & $\begin{array}{l}\text { - Pathological } \\
\text { Internet Use } \\
\text { Scale } \\
\text { (Morahan- } \\
\text { Martin \& } \\
\text { Schumacher, } \\
\text { 2000) } \\
\text { - Online time } \\
\text { spent the day } \\
\text { before } \\
\text { - Internet } \\
\text { Motivation } \\
\text { Scale (Wolfradt } \\
\text { \& Doll, 1999) } \\
\text { - question } \\
\text { about Internet } \\
\text { activities }\end{array}$ & SCC & $\begin{array}{l}\text { - Time spent } \\
\text { online } \\
\text { - Symptoms of } \\
\text { Internet } \\
\text { pathological } \\
\text { use } \\
\text { - Internet } \\
\text { activities } \\
\text { - Internet use } \\
\text { motivation. }\end{array}$ & Yes & $\begin{array}{l}\text { SCC - time spent online: } \\
r=-.26, p<.01 \\
\text { SCC- symptoms of Internet pathological } \\
\text { use: } r=-.40, p<.01 \\
\text { SCC - communication motive: } r=-.19, \\
p<.01 \\
\text { SCC - entertainment motive: } r=-.29, \\
p<.01 \\
\text { SCC - information motive: } r=.16, \\
p<.05 \\
\text { SCC - wasting time online }\left(r_{s}=-.18,\right. \\
p<.05), \text { music download }\left(r_{s}=-.18,\right. \\
p<.05), \text { instant messages }\left(r_{s}=-.16,\right. \\
p<.05), \text { online interaction with strangers } \\
\left(r_{s}=-.22, p<.05\right) \text {, having secret online } \\
\text { names or e-mail addresses }\left(r_{s}=-.17, p<\right. \\
.05)\end{array}$ \\
\hline \multicolumn{9}{|c|}{ Quinones \& Kakabadse (2015a); USA, UAE } \\
\hline $\begin{array}{l}\text { cross- } \\
\text { sectional }\end{array}$ & $\begin{array}{l}\text { USA: } \\
268 \\
\text { UAE: } \\
270\end{array}$ & $\begin{array}{l}\text { USA: } \\
50 \\
\text { UAE: } \\
45.5\end{array}$ & $18-65$ & $\begin{array}{l}\text { - Meerkerk et } \\
\text { al.'s (2010) } \\
\text { Compulsive } \\
\text { Internet Scale, } \\
\text { with } \\
2 \text { additional } \\
\text { items for } \\
\text { tolerance } \\
\text { - } 3 \text { items from } \\
\text { Caplan's (2003) }\end{array}$ & SCC & $\begin{array}{l}\text { - Compulsive } \\
\text { Internet use } \\
\text { - Preference for } \\
\text { virtual social } \\
\text { support }\end{array}$ & No & $\begin{array}{l}\text { SCC - Compulsive Internet Use: } \\
r_{\mathrm{US}}=-.55, p<.01 ; r_{\mathrm{UAE}}=-.44, p<.05 \\
\text { SCC - Preference for virtual social } \\
\text { support: } r_{\mathrm{US}}=-.44, p<.01 ; r_{\mathrm{UAE}}=-.41, \\
p<.01\end{array}$ \\
\hline
\end{tabular}




\begin{tabular}{|c|c|c|c|c|c|c|c|c|}
\hline & & & & $\begin{array}{l}\text { Preference for } \\
\text { Online } \\
\text { Interaction } \\
\text { Scale }\end{array}$ & & & & \\
\hline \multicolumn{9}{|c|}{ Quinones \& Kakabadse (2015b); UK, USA } \\
\hline $\begin{array}{l}\text { cross- } \\
\text { sectional }\end{array}$ & $\begin{array}{l}\text { UK: } \\
532 \\
\text { USA: } \\
502\end{array}$ & $\begin{array}{l}\text { UK: } \\
51.69 \\
\text { USA: } \\
49\end{array}$ & $18-65$ & $\begin{array}{l}\text { - The Revised } \\
\text { Version of } \\
\text { Meerkerk et } \\
\text { al.'s (2010) } \\
\text { Compulsive } \\
\text { Internet Scale, } \\
\text { with } \\
2 \text { additional } \\
\text { items for } \\
\text { tolerance } \\
\text { - } 3 \text { items from } \\
\text { Caplan's (2003) } \\
\text { Preference for } \\
\text { Online } \\
\text { Interaction } \\
\text { Scale }\end{array}$ & SCC & $\begin{array}{l}\text { - Compulsive } \\
\text { Internet Use } \\
\text { - Preference for } \\
\text { virtual } \\
\text { interactions }\end{array}$ & No & $\begin{array}{l}\text { SCC - Compulsive Internet Use: } \\
r_{\mathrm{UK}}=-.47, p<.01 \text { (employed); } \\
r_{\mathrm{UK}}=-.42, p<.01 \text { (unemployed); } \\
r_{\mathrm{USA}}=-.56, p<.01 \text { (employed); } \\
r_{\mathrm{USA}}=-.55, p<.01 \text { (unemployed) } \\
\text { SCC - preference for online interaction: } \\
r_{\mathrm{UK}}=-.35, p<.01 \text { (employed); } \\
r_{\mathrm{UK}}=-.32, p<.01 \text { (unemployed); } \\
r_{\mathrm{USA}}=.44, p<.01 \text { (employed); } \\
r_{\mathrm{USA}}=-.43, p<.01 \text { (unemployed) }\end{array}$ \\
\hline \multicolumn{9}{|c|}{ Shariff \& Khanekharab (2017); Malaysia } \\
\hline $\begin{array}{l}\text { cross- } \\
\text { sectional }\end{array}$ & 501 & 55.89 & $17-23$ & $\begin{array}{l}\text { - Mueller et al.'s } \\
\text { (2011) 8-item } \\
\text { Scale } \\
\text { (excessive SNS) } \\
\text { - The 11-item } \\
\text { modified } \\
\text { Compulsive } \\
\text { Buying Scale } \\
\text { (d'Astous et al., } \\
\text { 1990) }\end{array}$ & $\begin{array}{l}\text { Identity } \\
\text { confusion }\end{array}$ & $\begin{array}{l}\text { - Excessive SNS } \\
\text { usage } \\
\text { - Online } \\
\text { compulsive } \\
\text { buying }\end{array}$ & No & $\begin{array}{l}\text { Excessive SNS usage - SCC: } \\
B=.34, p<.01 \\
\text { SCC and materialism partially mediated } \\
\text { excessive SNS usage - online compulsive } \\
\text { buying relationship. } \\
(B=.14, p<.01,95 \% \mathrm{Cl}[.04, .23])\end{array}$ \\
\hline \multicolumn{9}{|c|}{ Šporčić, \& Glavak-Tkalić (2018); Croatia } \\
\hline $\begin{array}{l}\text { cross- } \\
\text { sectional }\end{array}$ & 509 & 8.8 & $18-40$ & $\begin{array}{l}\text { - Motives for } \\
\text { Online Gaming } \\
\text { Questionnaire } \\
\text { (Demetrovics et } \\
\text { al., 2011) } \\
\text { - Internet } \\
\text { Gaming } \\
\text { Disorder Scale } \\
\text { (Lemmens et } \\
\text { al., 2015) } \\
\text { - Questions } \\
\text { about gaming } \\
\text { behavior }\end{array}$ & SCC & $\begin{array}{l}\text { - Internet } \\
\text { gaming } \\
\text { disorder } \\
\text { - Motives for } \\
\text { Online Gaming } \\
\text { - Weekly } \\
\text { gaming time (h) }\end{array}$ & No & $\begin{array}{l}\text { SCC - IGD: } r=-.38, p<.01 \\
\text { SCC- escape motive: } r=-.39, p<.01 \\
\text { SCC - fantasy motive: } r=-.28, p<.01 \\
\text { SCC - weekly gaming: } r=-.22, p<.01\end{array}$ \\
\hline \multicolumn{9}{|c|}{ Stafford-Bush (2017); New Zealand } \\
\hline $\begin{array}{l}\text { cross- } \\
\text { sectional } \\
\text { and } \\
\text { qualitative } \\
\text { study }\end{array}$ & 12 & 100 & $14-18$ & $\begin{array}{l}\text { - Instagram } \\
\text { Questionnaire }\end{array}$ & SCC & $\begin{array}{l}\text { - Impression } \\
\text { management } \\
\text { on Instagram }\end{array}$ & $\begin{array}{l}\text { Yes } \\
\text { (prize } \\
\text { draw) }\end{array}$ & $\begin{array}{l}\text { SCC- frequency of Instagram photo } \\
\text { likes: } r=.16, p<.05 \\
\text { SCC - use of make-up in photos: } \\
r=.381, p<.05\end{array}$ \\
\hline \multicolumn{9}{|c|}{ Trask (2020); USA } \\
\hline $\begin{array}{l}\text { cross- } \\
\text { sectional }\end{array}$ & 563 & 62 & $17-50$ & $\begin{array}{l}\text { - Impressions of } \\
\text { Internet Users } \\
\text { Scale }\end{array}$ & SCC & $\begin{array}{l}\text { - Internet/ } \\
\text { Reality } \\
\text { Incongruency } \\
\text { - Negative } \\
\text { impressions of } \\
\text { Internet users } \\
\text { - Positive } \\
\text { impressions of } \\
\text { Internet users }\end{array}$ & Yes & $\begin{array}{l}\text { SCC - Internet/ Reality Incongruency: } \\
r=-.05, n s \\
\text { SCC - Negative impressions of Internet } \\
\text { users: } r=-.20, n s \\
\text { SCC - Positive impressions of Internet } \\
\text { users: } r=.31, p<.05\end{array}$ \\
\hline Valkenbur & Peter ( & 08); Th & etherlan & & & & & \\
\hline $\begin{array}{l}\text { cross- } \\
\text { sectional }\end{array}$ & 1,158 & 49.9 & $10-17$ & $\begin{array}{l}\text {-10 -item } \\
\text { questionnaire }\end{array}$ & $\begin{array}{l}\text { Self-concept } \\
\text { unity }\end{array}$ & $\begin{array}{l}\text { - Online } \\
\text { experiments }\end{array}$ & No & $\begin{array}{l}\text { Self-concept unity - online identity } \\
\text { experiments: } r=-.11, p<.01\end{array}$ \\
\hline
\end{tabular}




\begin{tabular}{|c|c|c|c|c|c|c|}
\hline 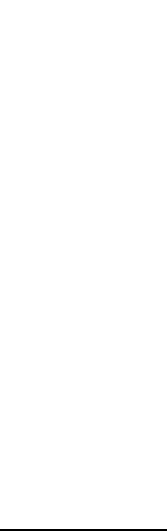 & & & & $\begin{array}{l}\text { for online } \\
\text { experiments } \\
-12 \text { items } \\
\text { created to } \\
\text { measure } \\
\text { adolescents' } \\
\text { tendency to } \\
\text { communicate } \\
\text { with people of } \\
\text { various ages } \\
\text { and cultural } \\
\text { backgrounds } \\
\text { when being } \\
\text { online. }\end{array}$ & $\begin{array}{l}\text { - Variety of } \\
\text { online } \\
\text { communication } \\
\text { partners }\end{array}$ & $\begin{array}{l}\text { Self-concept unity - variety of } \\
\text { communication partners: } r=-.04, n s\end{array}$ \\
\hline \multicolumn{7}{|c|}{ Yang \& Brown (2016); USA } \\
\hline $\begin{array}{l}\text { longitudinal } \\
\text { (test-retest) }\end{array}$ & $\begin{array}{l}218 \\
\text { At } \\
\text { follow } \\
\text {-up: } \\
135\end{array}$ & $\begin{array}{l}64 \\
\text { Follow } \\
\text {-up: } 69\end{array}$ & $\begin{array}{l}M= \\
18.07\end{array}$ & $\begin{array}{l}\text { - Revised Self- } \\
\text { Disclosure Scale } \\
\text { (Wheeless, } \\
\text { 1976, } \\
\text { 1978) and it } \\
\text { was also } \\
\text { developed a } \\
\text { breadth scale } \\
\text { - A 5-item scale } \\
\text { developed for } \\
\text { measuring the } \\
\text { perception of } \\
\text { supportive } \\
\text { Facebook } \\
\text { feedback } \\
\text { - Questions } \\
\text { about time } \\
\text { spent on } \\
\text { Facebook and } \\
\text { Facebook } \\
\text { friends }\end{array}$ & $\begin{array}{l}\text { - Dimensions of No } \\
\text { Facebook self- } \\
\text { presentation } \\
\text { - Supportive } \\
\text { online feedback }\end{array}$ & $\begin{array}{l}\text { SCC (T1) - supportive feedback: } \beta=.01 \text {, } \\
n s \\
\text { SCC (T2) - supportive feedback: } ß=.01 \text {, } \\
n s\end{array}$ \\
\hline
\end{tabular}

Note. SCC = Self-Concept Clarity. USA = United States of America. UK = United Kingdom. UAE = United Arab Emirates. SNS = Social Networking Sites. SWB = Subjective well-being. IGD =Internet Gaming Disorder. In all studies SCC was measured with Self Concept Clarity Scale (Campbell et al., 1996).

Table S2. Criteria for the Quality Assessment of the Studies Included in the Review Article "The Relationship Between Internet Use and Self-Concept Clarity: Systematic Review and Meta-Analysis."

\begin{tabular}{|c|c|c|c|c|c|c|c|}
\hline & $\begin{array}{l}\text { Item } \\
\text { No. }\end{array}$ & & $\begin{array}{l}\text { Yes (3 } \\
\text { points) }\end{array}$ & $\begin{array}{l}\text { No }(0 \\
\text { points) }\end{array}$ & $\begin{array}{l}\text { Uncertain } \\
\text { /Incomplete } \\
\text { (1/2 points)* }^{*}\end{array}$ & $\begin{array}{l}\text { Not } \\
\text { applying }\end{array}$ & Observations \\
\hline $\begin{array}{l}\text { Study design and } \\
\text { procedure }\end{array}$ & 1. & $\begin{array}{l}\text { Present key elements of study } \\
\text { design and procedure. }\end{array}$ & & & & & \\
\hline Setting & 2. & $\begin{array}{l}\text { Describe the setting and the } \\
\text { relevant dates, including periods } \\
\text { of recruitment }\end{array}$ & & & & & \\
\hline Participants & 3. & $\begin{array}{l}\text { Clearly define the criteria for } \\
\text { inclusion in the sample and } \\
\text { describe the study subjects }\end{array}$ & & & & & \\
\hline Variables & 4. & $\begin{array}{l}\text { Clearly define all the variables of } \\
\text { the study }\end{array}$ & & & & & \\
\hline Measurement & 5. & $\begin{array}{l}\text { Describe all the instruments } \\
\text { used, mentioning their } \\
\text { psychometric characteristics }\end{array}$ & & & & & \\
\hline Bias & 6. & $\begin{array}{l}\text { Describe efforts to identify and to } \\
\text { overcome potential sources of } \\
\text { bias }\end{array}$ & & & & & \\
\hline Study size & 7. & Estimate a priori the sample size & & & & & \\
\hline $\begin{array}{l}\text { Statistical } \\
\text { methods }\end{array}$ & 8. & $\begin{array}{l}\text { Performs appropriate statistical } \\
\text { analyzes }\end{array}$ & & & & & \\
\hline
\end{tabular}




\begin{tabular}{|c|c|c|c|c|c|c|c|}
\hline & $\begin{array}{l}\text { Item } \\
\text { No. }\end{array}$ & & $\begin{array}{l}\text { Yes (3 } \\
\text { points) }\end{array}$ & $\begin{array}{l}\text { No }(0 \\
\text { points) }\end{array}$ & $\begin{array}{l}\text { Uncertain } \\
\text { /Incomplete } \\
\text { (1/2 points)* }\end{array}$ & $\begin{array}{l}\text { Not } \\
\text { applying }\end{array}$ & Observations \\
\hline Participants & 9. & $\begin{array}{l}\text { (a) Mention numbers of } \\
\text { participants at each stage of } \\
\text { study } \\
\text { (b) Give reasons for non- } \\
\text { participation at each stage }\end{array}$ & & & & & \\
\hline Main results & 10. & $\begin{array}{l}\text { Report the relevant statistical } \\
\text { results according to the } \\
\text { procedure used }\end{array}$ & & & & & \\
\hline
\end{tabular}

Note. Items 1, 2, 4, 7 and 9 were based on the STROBE Statement (Vandenbroucke et al., 2007). Items 3, 5, 6, 8 were used or adapted from JBI Critical Appraisal Checklist for Analytical Cross Sectional Studies (Moola et al., 2017).

*In this section 1 or 2 points can be offered depending on the impact of the unclear/ incomplete information on the quality of the study. Fewer points mean a lower quality.

Table S3. Quality Assessment Results for Each Study Included in the Review Article "The Relationship Between Internet Use and Self-Concept Clarity: Systematic Review and Meta-Analysis."

\begin{tabular}{|c|c|c|c|c|c|c|c|c|c|c|c|c|}
\hline \multirow{2}{*}{ Studies } & \multicolumn{11}{|c|}{ Items } & \multirow{2}{*}{ Mean } \\
\hline & 1 & 2 & 3 & 4 & 5 & 6 & 7 & 8 & $9 a$ & $9 b$ & 10 & \\
\hline Adrianos, n.d. & 3 & 2 & 3 & 2 & 2 & 1 & 0 & 2 & 3 & NA & 2 & 2 \\
\hline Appel et al. (2018)-1 & 3 & 2 & 2 & 3 & 3 & 2 & 0 & 2 & 3 & 3 & 3 & 2.36 \\
\hline Appel et al. (2018)-2 & 3 & 2 & 3 & 3 & 3 & 2 & 0 & 2 & 3 & 3 & 3 & 2.45 \\
\hline Appel et al. (2018)-3 & 3 & 3 & 3 & 3 & 3 & 2 & 0 & 3 & 3 & 3 & 3 & 2.63 \\
\hline Davis (2013) & 2 & 3 & 2 & 2 & 3 & 2 & 0 & 1 & 3 & 3 & 2 & 2.09 \\
\hline Daniels (2014) & 3 & 2 & 3 & 3 & 3 & 1 & 3 & 3 & 3 & NA & 3 & 2.7 \\
\hline Drogos (2015) & 3 & 2 & 3 & 2 & 1 & 2 & 3 & 2 & 3 & 3 & 2 & 2.33 \\
\hline Lang (2012) & 3 & 2 & 3 & 3 & 3 & 3 & 0 & 3 & 3 & 3 & 2 & 2.58 \\
\hline Lee (2014) & 2 & 3 & 2 & 2 & 1 & 2 & 0 & 2 & 3 & 3 & 2 & 2 \\
\hline Lin et al. (2018) & 2 & 2 & 3 & 3 & 3 & 2 & 0 & 1 & 3 & 3 & 2 & 2.18 \\
\hline Matsuba (2006) & 2 & 2 & 2 & 3 & 3 & 1 & 0 & 2 & 3 & NA & 3 & 2.1 \\
\hline Israelshvili et al. (2012) & 2 & 2 & 3 & 3 & 3 & 3 & 0 & 2 & 3 & NA & 2 & 2.3 \\
\hline Fullwood et al. (2016) & 2 & 2 & 2 & 3 & 3 & 1 & 0 & 2 & NA & NA & 2 & 2 \\
\hline Quinones \& Kakabadse (2015a) & 3 & 2 & 3 & 3 & 3 & 3 & 0 & 2 & 3 & NA & 3 & 2.54 \\
\hline Quinones \& Kakabadse (2015b) & 2 & 2 & 3 & 3 & 3 & 3 & 3 & 2 & 3 & NA & 2 & 2.6 \\
\hline Ŝporĉić \& Glavak-Tkalić (2018) & 2 & 2 & 3 & 2 & 3 & 0 & 0 & 1 & 3 & 3 & 1 & 1.81 \\
\hline Shariff \& Khanekharab (2017) & 3 & 3 & 3 & 2 & 3 & 2 & 0 & 1 & NA & NA & 2 & 2.11 \\
\hline Stafford-Bush (2017) & 2 & 0 & 3 & 1 & 2 & 2 & 0 & 2 & 3 & 0 & 1 & 1.45 \\
\hline Trask (2020) & 3 & 3 & 3 & 3 & 3 & 0 & 0 & 3 & 2 & NA & 3 & 2.3 \\
\hline Valkenburg \& Peter (2008) & 2 & 3 & 3 & 3 & 3 & 1 & 0 & 1 & 3 & 3 & 2 & 2.18 \\
\hline Yang \& Brown (2016) & 2 & 3 & 3 & 3 & 3 & 3 & 0 & 2 & 3 & 2 & 3 & 2.45 \\
\hline
\end{tabular}

Table S4. Indicators of Meta-Analysis for the Review Article "The Relationship between Internet Use and Self-Concept Clarity: Systematic Review and Meta-Analysis."

\begin{tabular}{|c|c|c|c|c|c|c|c|c|c|c|c|c|c|c|}
\hline \multirow{2}{*}{ Model } & \multirow{2}{*}{$N$} & \multicolumn{3}{|c|}{ Effect size and $95 \% \mathrm{Cl}$} & \multicolumn{2}{|c|}{ Test of null (2-tail) } & \multicolumn{4}{|c|}{ Heterogeneity } & \multicolumn{4}{|c|}{$T^{2}$} \\
\hline & & Point estimate & LL & UL & $Z$ & $p$ & $Q$ & $d f$ & $p$ & $P^{2}$ & $T^{2}$ & $S E$ & Variance & $T$ \\
\hline Random & 11 & -0.35 & -0.44 & -0.24 & -6.41 & $<.01$ & 101.409 & 10 & $<.01$ & 90.139 & 0.03 & 0.017 & $<0.01$ & 0.17 \\
\hline
\end{tabular}


Table S5. Analysis of Categorical Moderators in the Review Article "The Relationship between Internet Use and Self-Concept Clarity: Systematic Review and Meta-Analysis"

\begin{tabular}{|c|c|c|c|c|c|c|c|c|c|}
\hline \multirow{2}{*}{ Moderators } & \multirow{2}{*}{$\begin{array}{l}\text { Number of } \\
\text { studies }\end{array}$} & \multicolumn{3}{|c|}{ Effect size and $95 \% \mathrm{Cl}$} & \multicolumn{2}{|c|}{ Test of null (2-tail) } & \multicolumn{3}{|c|}{ Heterogeneity } \\
\hline & & Point estimate & LL & UL & $z$ & $p$ & $Q$ & $d f$ & $p$ \\
\hline \multicolumn{10}{|c|}{ Cultural background } \\
\hline America & 3 & -0.514 & -0.597 & -0.419 & -9.216 & $<.001$ & & & \\
\hline Asia & 2 & -0.396 & -0.496 & -0.285 & -6.547 & $<.001$ & & & \\
\hline Europe & 6 & -0.241 & -0.380 & -0.090 & -3.098 & .002 & & & \\
\hline Total intergroup & & & & & & & 10.441 & 2 & .005 \\
\hline \multicolumn{10}{|c|}{ Internet operationalization } \\
\hline Dependence & 2 & -0.403 & -0.460 & -0.342 & -11.927 & $<.001$ & & & \\
\hline Intensity & 4 & -0.135 & -0.275 & -0.010 & -1.821 & .069 & & & \\
\hline Compulsive use & 5 & -0.487 & -0.547 & -0.423 & -12.744 & $<.001$ & & & \\
\hline Total intergroup & & & & & & & 21.541 & 2 & $<.001$ \\
\hline \multicolumn{10}{|l|}{ Presence of reward } \\
\hline Rewarded & 4 & -0.220 & -0.387 & -0.038 & -2.364 & .018 & & & \\
\hline Not rewarded & 7 & -0.417 & -0.506 & -0.319 & -7.644 & $<.001$ & & & \\
\hline Total intergroup & & & & & & & 3.957 & 1 & .047 \\
\hline \multicolumn{10}{|l|}{ Age range } \\
\hline Wide range & 6 & -0.454 & -0.527 & -0.375 & -10.045 & $<.001$ & & & \\
\hline Low range & 4 & -0.150 & -0.316 & 0.025 & -1.684 & .092 & & & \\
\hline Total intergroup & & & & & & & 10.992 & 1 & .001 \\
\hline \multicolumn{10}{|l|}{ Age category } \\
\hline $10-18$ years of age & 7 & -0.412 & -0.515 & -0.297 & -6.513 & $<.001$ & & & \\
\hline $18-65$ years of age & 2 & -0.215 & -0.461 & 0.062 & -1.524 & .128 & & & \\
\hline Total intergroup & & & & & & & 1.932 & 1 & .165 \\
\hline
\end{tabular}

Table S6. Analysis of Continuous Moderators in the Review Article "The Relationship between Internet Use and Self-Concept Clarity: Systematic Review and Meta-Analysis."

\begin{tabular}{|c|c|c|c|c|c|c|c|c|c|}
\hline & $\begin{array}{c}\text { Point } \\
\text { estimate }\end{array}$ & $S E$ & LL & UL & $Z$ & $p$ & $Q$ & $d f$ & $p$ \\
\hline \multicolumn{10}{|c|}{ Study quality } \\
\hline Slope & 0.156 & 0.379 & -0.586 & 0.900 & 0.413 & .679 & & & \\
\hline Intercept & -0.734 & 0.897 & -2.493 & 1.024 & -0.818 & .413 & & & \\
\hline$T^{2}$ & 0.036 & & & & & & & & \\
\hline Model & & & & & & & 0.170 & 1 & .679 \\
\hline Residual & & & & & & & 10.610 & 9 & .303 \\
\hline Total & & & & & & & 10.781 & 10 & .374 \\
\hline \multicolumn{10}{|c|}{ Sample size } \\
\hline Slope & -0.001 & $<0.001$ & -0.002 & $<0.001$ & -1.638 & .101 & & & \\
\hline Intercept & -0.137 & 0.460 & -0.460 & 0.185 & -0.834 & .404 & & & \\
\hline$T^{2}$ & 0.036 & & & & & & & & \\
\hline Model & & & & & & & 2.684 & 1 & .101 \\
\hline Residual & & & & & & & 11.255 & 11 & .422 \\
\hline Total & & & & & & & 13.939 & 12 & .304 \\
\hline
\end{tabular}




\section{Appendix B}

Table S7. PRISMA Checklist.

\begin{tabular}{|c|c|c|c|}
\hline Section/topic & \# & Checklist item & $\begin{array}{l}\text { Reported } \\
\text { on page } \\
\quad \#\end{array}$ \\
\hline \multicolumn{4}{|l|}{ TITLE } \\
\hline Title & 1 & Identify the report as a systematic review, meta-analysis, or both. & 1 \\
\hline \multicolumn{4}{|l|}{ ABSTRACT } \\
\hline Structured summary & 2 & $\begin{array}{l}\text { Provide a structured summary including, as applicable: background; objectives; } \\
\text { data sources; study eligibility criteria, participants, and interventions; study } \\
\text { appraisal and synthesis mTethods; results; limitations; conclusions and } \\
\text { implications of key findings; systematic review registration number. }\end{array}$ & 1 \\
\hline \multicolumn{4}{|l|}{ INTRODUCTION } \\
\hline Rationale & 3 & Describe the rationale for the review in the context of what is already known. & $1-2$ \\
\hline Objectives & 4 & $\begin{array}{l}\text { Provide an explicit statement of questions being addressed with reference to } \\
\text { participants, interventions, comparisons, outcomes, and study design (PICOS). }\end{array}$ & $N A * 2-4$ \\
\hline \multicolumn{4}{|l|}{ METHODS } \\
\hline $\begin{array}{l}\text { Protocol } \\
\text { and registration }\end{array}$ & 5 & $\begin{array}{l}\text { Indicate if a review protocol exists, if and where it can be accessed (e.g., Web } \\
\text { address), and, if available, provide registration information including registration } \\
\text { number. }\end{array}$ & 4 \\
\hline Eligibility criteria & 6 & $\begin{array}{l}\text { Specify study characteristics (e.g., PICOS, length of follow-up) and report } \\
\text { characteristics (e.g., years considered, language, publication status) used as criteria } \\
\text { for eligibility, giving rationale. }\end{array}$ & $4-5$ \\
\hline Information sources & 7 & $\begin{array}{l}\text { Describe all information sources (e.g., databases with dates of coverage, contact } \\
\text { with study authors to identify additional studies) in the search and date last } \\
\text { searched. }\end{array}$ & 4 \\
\hline Search & 8 & $\begin{array}{l}\text { Present full electronic search strategy for at least one database, including any } \\
\text { limits used, such that it could be repeated. }\end{array}$ & 4 \\
\hline Study selection & 9 & $\begin{array}{l}\text { State the process for selecting studies (i.e., screening, eligibility, included in } \\
\text { systematic review, and, if applicable, included in the meta-analysis). }\end{array}$ & $4-5$ \\
\hline $\begin{array}{l}\text { Data collection } \\
\text { process }\end{array}$ & 10 & $\begin{array}{l}\text { Describe method of data extraction from reports (e.g., piloted forms, } \\
\text { independently, in duplicate) and any processes for obtaining and confirming data } \\
\text { from investigators. }\end{array}$ & 5 \\
\hline Data items & 11 & $\begin{array}{l}\text { List and define all variables for which data were sought (e.g., PICOS, funding } \\
\text { sources) and any assumptions and simplifications made. }\end{array}$ & 4 \\
\hline $\begin{array}{l}\text { Risk of bias in } \\
\text { individual studies }\end{array}$ & 12 & $\begin{array}{l}\text { Describe methods used for assessing risk of bias of individual studies (including } \\
\text { specification of whether this was done at the study or outcome level), and how this } \\
\text { information is to be used in any data synthesis. }\end{array}$ & 5 \\
\hline Summary measures & 13 & State the principal summary measures (e.g., risk ratio, difference in means). & $5-6$ \\
\hline Synthesis of results & 14 & $\begin{array}{l}\text { Describe the methods of handling data and combining results of studies, if done, } \\
\text { including measures of consistency }\left(\text { e.g., } I^{2}\right) \text { for each meta-analysis. }\end{array}$ & $5-6$ \\
\hline $\begin{array}{l}\text { Risk of bias across } \\
\text { studies }\end{array}$ & 15 & $\begin{array}{l}\text { Specify any assessment of risk of bias that may affect the cumulative evidence } \\
\text { (e.g., publication bias, selective reporting within studies). }\end{array}$ & 6 \\
\hline Additional analyses & 16 & $\begin{array}{l}\text { Describe methods of additional analyses (e.g., sensitivity or subgroup analyses, } \\
\text { meta-regression), if done, indicating which were pre-specified. }\end{array}$ & $5-6$ \\
\hline
\end{tabular}

\section{RESULTS}

Study selection

17 Give numbers of studies screened, assessed for eligibility, and included in the review, with reasons for exclusions at each stage, ideally with a flow diagram.

For each study, present characteristics for which data were extracted (e.g., study

Study characteristics 
Results of individual studies

Synthesis of results studies

Additional analysis
For all outcomes considered (benefits or harms), present, for each study: (a) simple

20 summary data for each intervention group (b) effect estimates and confidence intervals, ideally with a forest plot.

Present results of each meta-analysis done, including confidence intervals and measures of consistency.

22 Present results of any assessment of risk of bias across studies (see Item 15).

Give results of additional analyses, if done (e.g., sensitivity or subgroup analyses, meta-regression [see Item 16]).
$9-11 * *$

Appendix

A, Table S4

\section{DISCUSSION}

Summary of evidence

Summarize the main findings including the strength of evidence for each main

24 outcome; consider their relevance to key groups (e.g., healthcare providers, users, and policy makers).

Limitations

Discuss limitations at study and outcome level (e.g., risk of bias), and at reviewlevel (e.g., incomplete retrieval of identified research, reporting bias).

Provide a general interpretation of the results in the context of other evidence, and implications for future research.

Conclusions

\section{FUNDING}

Funding

From: Moher, D., Liberati, A., Tetzlaff, J., Altman, D. G., \& The PRISMA Group. (2009). Preferred Reporting Items for Systematic Reviews and Meta-Analyses: The PRISMA Statement. PLoS Med, 6(7): Article e1000097. https://doi.org/10.1371/journal.pmed.1000097

For more information, visit: www.prisma-statement.org.

*PICOS standards are not applicable. The research questions are presented, but not in accordance with PICOS.

**There were no intervention groups. 


\section{Correspondence to:}

Cristina Elena Petre

Faculty of Psychology and Educational Sciences, University of Bucharest

Street Șoseaua Panduri no. 9, Sector 5

City Bucharest, Postal code 50663

Country Romania

Email: cristina.elena.petre(at)drd.unibuc.ro

Editorial record: First submission received on September 28, 2019. Revisions received on November 15, 2020 and January 18, 2021. Accepted for publication on February 12, 2021.

Editor in charge: Kristian Daneback

\section{About Author}

Cristina Elena Petre is a doctoral student in psychology at Faculty of Psychology and Educational Sciences, University of Bucharest, Romania. She also works as a clinical psychologist. 